\title{
Effects of argon ion sputtering on the surface of
}

\section{graphene/polyethylene composites}

\author{
A. Ansón-Casaos ${ }^{1 *}$, E. Aylón ${ }^{1}$, R. Ríos ${ }^{2}$, J.A. Puértolas ${ }^{2}$ \\ ${ }^{1}$ Instituto de Carboquímica, ICB-CSIC, Miguel Luesma Castán 4, 50018 Zaragoza, Spain \\ ${ }^{2}$ Instituto de Investigación en Ingeniería de Aragón, I3A, Universidad de Zaragoza, \\ 50018 Zaragoza, Spain
}

*Email address: alanson@icb.csic.es

\begin{abstract}
Argon ion sputtering at various energies in the range of $500-5000 \mathrm{eV}$ is performed on polymer composites of ultra-high molecular weight polyethylene (UHMWPE) with 4.6 wt.\% graphene nanoplatelets (GNPs). X-ray photoelectron spectroscopy (XPS) shows that irradiation above $3000 \mathrm{eV}$ causes an abrupt transition from tetrahedral $\mathrm{sp}^{3}$ into planar $\mathrm{sp}^{2}$ carbon in the blank polyethylene surface. This graphitization process, as well as the formation of certain oxygen groups after the subsequent exposure to air, is delayed by graphene in the composites. Besides, both XPS and Raman spectroscopy indicate that a part of the $\mathrm{sp}^{2}$ graphene network is transformed into $\mathrm{sp}^{3}$ carbon defects by irradiation. Surface hardness and Young's modulus increase by $30-100 \%$ in blank polyethylene and the composites upon irradiation. The surface electrical resistance of polyethylene decreases from $10^{15}$ to $10^{8} \Omega$ by sputtering at $5000 \mathrm{eV}$. Composites that are consolidated at low temperature $\left(175^{\circ} \mathrm{C}\right)$ experience a transition from insulating $\left(10^{15} \Omega\right)$ to conducting $\left(10^{4} \Omega\right)$ in a narrow range of $\mathrm{Ar}^{+}$sputtering energies, while for a high consolidation
\end{abstract}


temperature $\left(240{ }^{\circ} \mathrm{C}\right)$ the transition is not observed. This research provides information on the induced interaction mechanisms between graphene and a polymer matrix upon ion beam irradiation.

KEYWORDS: UHMWPE; graphene; argon beam; XPS; nanoindentation; electrical conductivity

\section{Introduction}

The control of defects in graphene-like materials is a key issue, since it allows tuning their intrinsic properties towards the development of new potential applications [1]. In addition to the unavoidable creation of defects during graphene growth or processing, different routes such as irradiation, chemical treatments [2] and mechanical strain [3] can deliberately generate single and multiple vacancies, Stone-Wales defects, one dimensional defects at the edges, etc. Among irradiation strategies, the electron beam from an electron microscope can be used to simultaneously produce and observe vacancies in graphene [4]. Alternatively, beams of energetic ions or atoms can induce point defects and be used for patterning, cutting, metal deposition and functionalization. The effects of noble gas ions, including $\mathrm{Ar}^{+}$beams, at different doses and energies ranging from tens of $\mathrm{eV}$ to $\mathrm{MeV}$ have been studied by Raman spectroscopy and atomistic simulations in graphene, two-layered graphene and multi-layered graphene [5-7].

It is expected that the mechanical properties of pristine graphene should be strongly affected by defects, regardless of the causing agent. Several works deal with the elastic and plastic behavior, as well as the fracture mechanisms, of defective graphene [8-11]. The outcomes usually point out a drop in the mechanical performance as the induced defect concentration increases. An improvement in the mechanical properties upon irradiation in graphene-related materials is unusual. In some cases, irradiation can lead to 
self-organization or self-assembly through the generation of covalent bonds, as it is described for carbon nanotubes in the review by Krasheninnikov et al. [12]. Also, LópezPolín et al. [13] experimentally found an increase in the Young modulus of a suspended graphene layer when the $\mathrm{Ar}^{+}$bombardment achieved a critical defect density. Apart from the mechanical properties, the in-plane conductivity of graphene can be substantially decreased upon the creation of defects. It is usually considered that losses in the charge carrier mobility are already measurable when vacancies occupy a $0.01-0.1 \%$ of the total area [1]. In graphene self-standing films, structural integrity of graphene is even more important than lateral size to achieve high transport characteristics [14]. However, it has been observed that the effects of oxygen plasma on the electrical conductivity are minimized for multi-layered graphene, since only the outmost layer is significantly affected, while the deepest graphene layers and thus the electrical conductivity are in part protected against irradiation [15].

In structural polymers, the exposure to energetic ions with energies around $1000 \mathrm{eV}$ has been largely described in the literature as giving rise to processes such as scissoring with generation of radicals, bonding, branching, cross-linking, dehydrogenation and sputtering of fragments $[16,17]$. X-ray photoelectron spectroscopy (XPS) indicates that the surface of high density polyethylene chemically changes upon $\mathrm{Ar}^{+}$treatment, from the initial chain of single bonds to a graphite-like structure, through the progressive appearance of $\mathrm{C}=\mathrm{C}$ double bonds $[18,19]$. In polypropylene, it has been shown that the transformation leads to a great decrease in the surface electrical resistance. The mechanism of conductivity has been described as hopping processes between conducting clusters, which seem to be connected to each other in a non-random way [20].

Therefore, it can be considered that the behavior of graphene and polymeric systems under $\mathrm{Ar}^{+}$bombardment has been studied independently. However, the microstructural and macroscopic effects in the composites have not been evaluated in the literature. 
Graphene/polyethylene composites have demonstrated applications as structural biomaterials [21], which may need surface treatments and sterilization by irradiation protocols $[22,23]$. Similar sterilization processes are used on food packaging materials [24], which take advantage of their gas barrier properties [25]. In addition, graphene/polyethylene composites find applications in components with electromagnetic interference shielding and electrostatic discharge requirements [25]. The objective of this work is to investigate whether $\mathrm{Ar}^{+}$sputtering on the composite might induce new interaction mechanisms between the filler and the matrix that influence the mechanical and electrical surface properties.

\section{Materials and methods}

\subsection{Materials}

Medical grade ultra-high molecular weight polyethylene (UHMWPE) powder (GUR1050 ${ }^{\circledR}$ grade) was supplied by Celanese. The density is $0.934 \mathrm{~g} / \mathrm{cm}^{3}$ and the molecular weight is 8.6 $10^{6} \mathrm{~g} / \mathrm{mol}$. The filler was a multi-layered nanoplatelet graphene (GNP) material (avanPLAT-40 ${ }^{\circledR}$ ) from Avanzare, Spain, which was synthesized by mechanical exfoliation of graphite. According to the provider specifications, the GNP has a lateral size of $40 \mu \mathrm{m}$ and an average thickness around $10 \mathrm{~nm}$, and each particle consists of $\leq 30$ layers.

\subsection{Composite consolidation}

The GNP material was thoroughly mixed with polyethylene in a blade mixer, following a previous work [26]. The GNP concentration in graphene/polyethylene composites was set at 4.6 wt.\%; this quantity of GNP is high enough to investigate the effects of $\mathrm{Ar}^{+}$on the interactions with the polyethylene matrix. The powders were put in a circular mold $(\varnothing=$ $90 \mathrm{~mm}$ ) and pressed in a hot platen press (Specac, Slough, UK) at $15 \mathrm{MPa}$ for $30 \mathrm{~min}$. 
Two different consolidation temperatures, $175^{\circ} \mathrm{C}$ and $240^{\circ} \mathrm{C}$ (HT label), were tested to observe possible effects on the GNP distribution in the polymer matrix. The thickness of the composite layer (GR/PE and GR/HTPE) was $1 \mathrm{~mm}$, and it was supported in $3 \mathrm{~mm}$ of pure polyethylene. Consequently, the total specimen thickness was $4 \mathrm{~mm}$ and the GNP amount with respect to the total was $1 \mathrm{wt} . \%$. The notation for all the considered materials is included in Table 1. Consolidated cylinders were cut into rectangular specimens (approximately $13 \times 9 \times 4 \mathrm{~mm}^{3}$ ) before the exposure to the argon ion beam.

\subsection{Treatment with the argon ion beam and XPS measurements}

An ESCAPlus Omicron spectrometer provided with a Mg anode $(1253.6 \mathrm{eV})$ was utilized for both $\mathrm{Ar}^{+}$treatments and XPS measurements. The GNP powder, blank PE, GR/PE and GR/HTPE composite specimens were treated by $\mathrm{Ar}^{+}$sputtering and subsequently analyzed by XPS in the high vacuum chamber, thus without air contact.

The $\mathrm{Ar}^{+}$source was located at a distance of approximately $25 \mathrm{~cm}$ from the target, with an incident angle of $45^{\circ}$. The sputtering treatment was performed under high vacuum conditions $\left(10^{-9}-10^{-10}\right.$ torr). The $\mathrm{Ar}^{+}$current intensity was constant for all the experiments, keeping the source intensity at $25 \mathrm{~mA}$. The beam spot was adjusted to cover the largest face of a rectangular specimen. Exposure to the $\mathrm{Ar}^{+}$beam was performed at steps of 5 min, different energies in the range of 500 to $5000 \mathrm{eV}$, and two working modes: i) a single step of 5 min at a given energy $\left(E_{\mathrm{Ar}}\right)$, and ii) accumulated steps in a sequence of increasing $E_{\mathrm{Ar}}$ up to $5000 \mathrm{eV}$, which means accumulated $\mathrm{Ar}^{+}$dosages, with a delay of approximately 20 min between irradiation steps. Therefore, two parameters control the intensity of the treatment: the energy of incident particles, which is given by the acceleration voltage, and the flow of incident particles, which in this work is given by the number of exposure stages. The conditions and specimen labels are summarized in Table 1. 
The XPS analysis was performed in-situ for all the one-step experiments and after each one of the irradiation stages in the accumulative experiments. The top surface of PE specimens was bridged to the metal XPS support by a copper wire to facilitate charge dissipation. The binding energy (BE) of PE spectra was not further corrected for charge accumulation. The BE in GR/PE and GR/HTPE specimens was corrected with the position of graphitic carbon at $284.4 \mathrm{eV}$ after the highest energy irradiation, and all the other spectra for the sample were corrected accordingly. The Casa XPS software was utilized for spectrum analysis and deconvolution. After XPS analysis, specimens were taken out from the XPS vacuum chamber to be analyzed by the other techniques under ambient conditions.

\subsection{Spectroscopic and thermal characterization}

Fourier-transform infrared (IR) spectroscopy was performed in a Bruker Vertex 70 spectrometer. Consolidated surfaces were measured in an attenuated total reflectance (ATR) configuration. The investigated range was $600-4000 \mathrm{~cm}^{-1}$ with a resolution of $2 \mathrm{~cm}^{-}$ 1 .

Raman spectra were obtained by means of a HORIBA Jobin Yvon Raman spectrometer HR 800UV. The measuring parameters were set as follows: laser wavelength $=532 \mathrm{~nm}$, hole $=500 \mu \mathrm{m}$, grating $=600$ lines $/ \mathrm{mm}$, exposition $=5 \mathrm{~s}$, accumulation $=5$ acquisitions . The incident power was $0.26 \mathrm{~mW}$. Optical microscopy images of $110 \mathrm{x} 140 \mu \mathrm{m}^{2}$ were taken using a 50x objective under a halogen lamp illumination.

Thermogravimetric experiments were conducted in a Q5000 thermobalance by TA Instruments (accuracy: $10^{-4} \mathrm{mg}$ ) from room temperature to $600^{\circ} \mathrm{C}$ at a heating rate of 10 ${ }^{\circ} \mathrm{C} / \mathrm{min}$ under air atmosphere. The outcomes are plotted in terms of the weight loss fraction $(\alpha)$ as a function of the temperature:

$\alpha=\left(W_{\mathrm{i}}-W_{T}\right) / W_{i}$ 
where $W_{\mathrm{i}}$ is the initial weight and $W_{T}$ is the weight at temperature $T$.

\subsection{Surface mechanical properties}

Nanoindentation assays were performed for the assessment of changes in hardness and elastic modulus compared to pristine PE. In-depth profiles were obtained using a G200 nanoindenter (Agilent Tecnologies, Englewood, Colorado, USA) in the Continuous Stiffness Measurement (CSM) mode. The maximum programmed depth was $1500 \mathrm{~nm}$ and the indentation rate was $5 \mathrm{~nm} / \mathrm{s}$.

Vickers hardness was measured with a micro-hardness tester (Matsuzawa Digital Microhardness Tester MXT70, Matsuzawa Co., Akita, Japan). A standard Vickers indenter was utilized with a load of $100 \mathrm{~g}$ and an indentation time of $15 \mathrm{~s}$. An average value of at least three measurements and their standard deviation is presented in this work for each specimen.

Average surface roughness $\left(R_{\mathrm{a}}\right)$ was measured with a confocal microscope Sensofar PLm 230D (Sensofar, Barcelona, Spain).

\subsection{Surface electrical resistance}

The electrical conductivity was evaluated through the measurement of surface resistance by a two point probe method. Measurements were performed with a Keithley 4200-SCS machine provided with two source measurement units and a pre-amplifier. A potential difference of $20 \mathrm{~V}$ was probed on the specimen surface by two tungsten needles at a distance of $2 \mathrm{~mm}$, and the electrical current was measured. In all the cases, the resistance values were high enough to neglect the contact resistances between the probes and the specimen.

\section{Results}




\subsection{XPS profiles}

The effect of the $\mathrm{Ar}^{+}$gun on GNP powders, blank PE, GR/PE and GR/HTPE composites was first studied in situ by XPS. The relevant information is mostly extracted from the C 1s spectral region. Figure 1 includes most of the spectra, while certain treatments (Table 1) are not plotted just for clarity. Two main characteristics have to be noticed from the high resolution C 1s spectra:

i) The energy position of the peak. Binding energies (BEs) for graphitic $\mathrm{sp}^{2}$ and aliphatic $\mathrm{sp}^{3}$ carbon are expected around 284.6 and $285.1 \mathrm{eV}$ respectively [27]. In addition, an upshift in the XPS peaks can be associated to a lack of charge dissipation in the surface, which is ultimately related to the surface electrical resistance. Energy shifts due to charge accumulation provide qualitative information about surface resistance that is relevant for the present study.

ii) The shape of the peak. A pure tetrahedral $\mathrm{sp}^{3}$ carbon peak is expected to be symmetric $[19,20]$. On the contrary, a graphitic $\mathrm{sp}^{2}$ peak is intrinsically asymmetric, with a long tail extending towards high BEs due to electronic effects that can be ultimately associated with a high electrical conductivity $[28,29]$. Most carbon materials typically show asymmetric $\mathrm{C} 1 \mathrm{~s}$ profiles that result from the joint contributions of $\mathrm{sp}^{3}$ and $\mathrm{sp}^{2}$ carbon.

According to the above concepts, the starting spectrum of GNP powders looks like that of $\mathrm{sp}^{2}$ graphite [28]. The $\mathrm{C} 1 \mathrm{~s}$ peak is quite sharp and asymmetric, and it is located at 284.3 $\mathrm{eV}$. When the GNP powder is irradiated with energies up to $1500 \mathrm{eV}$, the peak intensity decreases and it becomes wider. The peak change indicates the generation of defects in the graphene structure [30] until achieving a certain limiting level at approximately $1500 \mathrm{eV}$. For higher acceleration voltages up to $5000 \mathrm{eV}$, the peak remains nearly unchanged.

On the other hand, the initial spectrum of PE is symmetric, and it appears at a BE of 295.4 $\mathrm{eV}$ because of the insulating character of PE. The $\mathrm{C}$ 1s peak of the other blank sample 
HTPE is symmetric too, just with a slightly larger width than PE (FWHM $=1.51$ and 1.60 $\mathrm{eV}$ respectively). In PE, as the surface is irradiated, the peak becomes asymmetric and shifts to the position of graphite materials. The peak maximum reaches the $\mathrm{BE}$ of $284.4 \mathrm{eV}$ after the treatment with $E_{\mathrm{Ar}}$ of around $4000 \mathrm{eV}$, with an abrupt transition between 3000 and $4000 \mathrm{eV}$. The accumulated treatment is quite similar to the one-step experiments, although the final peak shape is more clearly achieved at $4000 \mathrm{eV}$ and thus identical spectra are provided after treatments at 4000 and $5000 \mathrm{eV}$.

The spectra of the untreated GR/PE and GR/HTPE materials are a combination of the components. The graphene $\mathrm{sp}^{2}$ and polyethylene $\mathrm{sp}^{3}$ contributions are separated by $2.2 \mathrm{eV}$ in GR/PE and $1.2 \mathrm{eV}$ in GR/HTPE. The $\mathrm{C} 1 \mathrm{~s}$ peak in GR/PE is located at $+7 \mathrm{eV}$ from its theoretical BE, indicating substantial charge accumulation during the XPS measurement. In the case of the GR/HTPE specimen, the $\mathrm{C} 1 \mathrm{~s}$ peak is located at $+2.3 \mathrm{eV}$ from the theoretical BE of $285.1 \mathrm{eV}$. Both the GR/PE and GR/HTPE C 1s spectra shift towards the graphite position at $284.4 \mathrm{eV}$ upon ion beam treatments of increasing energies. After irradiation with energies higher than $3500 \mathrm{eV}$, the peak shape looks like PE after analogous ion beam treatments. As in blank PE, the accumulated and the one step experiments in the composites ultimately lead to similar effects.

For a quantitative analysis of changes occurring in the $\mathrm{C} 1 \mathrm{~s}$ peak upon $\mathrm{Ar}^{+}$beam irradiation, the profile was interpreted following an identical procedure in all the specimens. Two main components were considered for the peak decomposition (Figure 2.a): an asymmetric $\mathrm{sp}^{2}$ contribution at the lowest BEs and a symmetric $\mathrm{sp}^{3}$ contribution at approximately $+0.6 \mathrm{eV}$ over the $\mathrm{sp}^{2}$ component. In addition, some of the specimens required a small shake-up contribution at approximately $+5 \mathrm{eV}[31]$. The $\mathrm{sp}^{2}$ contribution was modeled by a Lorentzian asymmetric line-shape. The symmetric $\mathrm{sp}^{3}$ contribution and the small shake-up were fitted to Gaussian/Lorentzian product functions with a combination of $40-60 \%$ Gaussian-Lorentzian. The parameters of energy position and 
width were allowed to vary until the best fit to the experimental profile. The areal $\%$ of the $\mathrm{sp}^{2}$ component was calculated and it is plotted vs. $E_{\mathrm{Ar}}$ in Figure 2.

In the GNP powder, the $\mathrm{C} 1 \mathrm{~s}$ peak can be well-fitted to a nearly pure $\mathrm{sp}^{2}$ component $\left(92.9 \%\right.$ area) with a small contribution of $\mathrm{sp}^{3}(3.6 \%)$ and the shake-up (3.5\%). Upon irradiation at $1500 \mathrm{eV}$, the $\mathrm{sp}^{2}$ component decreases to around $60 \%$ and it remains at the level of $70 \%$ up to the maximum tested energy of $5000 \mathrm{eV}$. In the high vacuum chamber, where no heteroatoms are available, the $\mathrm{sp}^{3}$ component has to be associated with bonds between nearby graphene sheets.

In $\mathrm{PE}$, the initial $\mathrm{C} 1 \mathrm{~s}$ spectrum is given by pure $\mathrm{sp}^{3}$ carbon. Both one step and accumulated treatments reach a maximum of approximately $80 \%$ of $\mathrm{sp}^{2}$ carbon after irradiation at $5000 \mathrm{eV}$. As previously mentioned, a sharp transition from $\mathrm{sp}^{3}$ to $\mathrm{sp}^{2}$ is observed for $\mathrm{Ar}^{+}$energies of $3000-4000 \mathrm{eV}$ in one-step experiments, while it starts at around $2000 \mathrm{eV}$ in the accumulated treatment. Therefore, it is evidenced that an increase in the $\mathrm{Ar}^{+}$density can promote the generation of surface defects as $\mathrm{sp}^{2}$ carbon.

In the untreated GR/PE and GR/HTPE composites, the areal $\mathrm{sp}^{2}$ contribution is in the range of $10-40 \%$. The energy effect is not efficient in the generation of $\mathrm{sp}^{2}$ carbon, since a single exposure of $3000 \mathrm{eV}$ for 5 min does not produce a significant damage in the $\mathrm{sp}^{3}$ carbon network. Moreover, the presence of graphene in the composite hinders the conversion of $\mathrm{sp}^{3}$ to $\mathrm{sp}^{2}$ carbon upon irradiation with energies higher than $3000 \mathrm{eV}$. The $\mathrm{sp}^{2}$ area in the GR/PE surface reaches values around $70 \%$ only after the accumulated treatment at $5000 \mathrm{eV}$. In the GR/HTPE material, the transformation does not reach the level of $60 \%$ area of the $\mathrm{sp}^{2}$ component, even in the accumulated experiment.

\subsection{IR and Raman spectroscopy}

In this section, some representative spectra are shown to further discuss the structural effects of $\mathrm{Ar}^{+}$sputtering on the surface of graphene composites. Typically, the chosen 
spectra provide a comparison between untreated materials and the highest energy sputtering treatments, where changes are most clearly observed. While XPS was done in situ, IR and Raman spectroscopy had to be performed outside the high vacuum chamber. Thus, the specimens were exposed to the air before the measurements, and some of the defects previously created by the $\mathrm{Ar}^{+}$beam can react with oxygen and transform into different surface chemical groups.

The main IR characteristics of polyethylene are detected in all the specimens: the methylene C-H asymmetric/symmetric stretching at 2918/2849 $\mathrm{cm}^{-1}$, methylene C-H bending at $1473 / 1463 \mathrm{~cm}^{-1}$, and methylene $-\left(\mathrm{CH}_{2}\right)_{\mathrm{n}^{-}}$rocking at $721 \mathrm{~cm}^{-1}$ [26]. As a general feature, the absorbance of intrinsic polyethylene bands decreases with the $\mathrm{Ar}^{+}$beam treatment, indicating a disruption in polyethylene chains (Figure 3). Apart from quantitative changes in intrinsic bands, other qualitative changes are observed in the IR spectra at a relatively small absorbance scale. The PE material after the $\mathrm{Ar}^{+}$beam treatment shows new bands in the regions of 3420 and $1100-1400 \mathrm{~cm}^{-1}$, together with peaks of increased intensities at 1713 and $965 \mathrm{~cm}^{-1}$. The peak at $965 \mathrm{~cm}^{-1}$ is due to transvinylene groups generated by the partial dehydrogenation of polyethylene chains. The bands at 3420,1713 and $1100-1400 \mathrm{~cm}^{-1}$ are associated to different oxygen chemical groups that are produced through the reaction of oxygen from air with the irradiated PE surface. Hydroxyl $\left(3420 \mathrm{~cm}^{-1}\right)$ and carbonyl $\left(1713 \mathrm{~cm}^{-1}\right)$ groups are observed in the PE4000 specimen, while the alcohol bands at $1100-1400 \mathrm{~cm}^{-1}$ are further developed in the most strongly treated PE-5000A specimen. The trans-vinylene peak is also intense after the accumulated experiment.

The presence of graphene in GR/PE and GR/HTPE composites leads to the appearance of the $\mathrm{C}=\mathrm{C}$ band at around $1570 \mathrm{~cm}^{-1}$. Graphene by itself does not produce any other noticeable changes in the PE and HTPE spectra. When the composite materials are sputtered with the $\mathrm{Ar}^{+}$beam, a peak around $1710 \mathrm{~cm}^{-1}$ develops like in the treated PE, 
whose intensity depends on the $\mathrm{Ar}^{+}$energy. Similar observations have been reported on composites of multi-walled carbon nanotubes and ultra-high density polyethylene upon an argon plasma treatment [32]. However, in our experiments the growth of bands at 3420 , 1400-1100 and $965 \mathrm{~cm}^{-1}$ seems to be hindered by graphene, particularly in the GR/HTPE5000A specimen. Therefore, graphene has an influence against the effects of the $\mathrm{Ar}^{+}$ density.

The Raman spectrum of PE shows prominent features in the regions of $1000-1500 \mathrm{~cm}^{-1}$ and $2700-3000 \mathrm{~cm}^{-1}$ (Figure 4). The first region includes at least four sharp peaks at 1060 , 1128,1294 and $1438 \mathrm{~cm}^{-1}$. The second region includes two sharp peaks at 2847 and 2881 $\mathrm{cm}^{-1}$, a shoulder at around $2930 \mathrm{~cm}^{-1}$ and a small band at $2720 \mathrm{~cm}^{-1}$. Upon $\mathrm{Ar}^{+}$sputtering, some broad bands appear in the region of $500-2000 \mathrm{~cm}^{-1}$, which are particularly clear in the PE-5000A specimen: 690, 1060 and $1600 \mathrm{~cm}^{-1}$. The band at around $1600 \mathrm{~cm}^{-1}$ is reminiscent of the $\mathrm{G}$ band, which is typically observed in carbon materials, and might be associated to the generation of a graphite-like network of $\mathrm{C}=\mathrm{C}$ bonds. The origin of the other features is unclear since there are not analogous features in most common carbon materials [33].

Since the lateral size of GNPs reaches $40 \mu \mathrm{m}$ and the laser spot in Raman measurements is approximately of $1 \mu \mathrm{m}$, Raman spectra of the graphene component can be separately measured in the surface of composite specimens. Optical microscopy images under a halogen lamp show bright regions that can be associated to graphene, and dark regions where the Raman spectrum shows polyethylene features, including bands at 690, 1050 and $1630 \mathrm{~cm}^{-1}$ in $\mathrm{Ar}^{+}$treated specimens (Figure 5). In bright regions of optical microscopy images, Raman spectra directly show features of the graphene component, including the D band at $1345 \mathrm{~cm}^{-1}, \mathrm{G}$ band at $1579 \mathrm{~cm}^{-1}$ and 2D band at $2715 \mathrm{~cm}^{-1}$ (Figure 5). It can be observed that the intensity (I) of the $\mathrm{D}$ and 2D bands changes upon $\mathrm{Ar}^{+}$sputtering compared to the $G$ band. The $I_{D} / I_{G}$ ratio increases and the $I_{2 D} / I_{G}$ ratio decreases indicating 
the generation of defects in relatively high crystallinity graphene [33]. In particular, the accumulated experiment GR/HTPE-5000A shows the largest changes in the $\mathrm{I}_{\mathrm{D}} / \mathrm{I}_{\mathrm{G}}$ and the $\mathrm{I}_{2 \mathrm{D}} / \mathrm{I}_{\mathrm{G}}$ ratios. Here, the effect of $\mathrm{Ar}^{+}$dosage makes a difference with respect to the effect of the $\mathrm{Ar}^{+}$incident energy.

\subsection{Thermo-oxidative characterization}

The thermo-oxidative stability of non-irradiated PE, HTPE, GR/PE and GR/HTPE specimens was studied by thermogravimetric analysis (TGA) under air flow. The objective was to identify effects of graphene and the consolidation temperature that will be later associated with the behavior under $\mathrm{Ar}^{+}$sputtering.

The TGA profile for all the samples shows three remarkable features (Figure 6) [34]: i) a small weight rise due to oxygen chemisorption in the range of $200-250^{\circ} \mathrm{C}$; ii) a moderate weight loss due to the polymer oxidative degradation in the range of $300-400^{\circ} \mathrm{C}$; and iii) a great weight loss due to thermal degradation at around $450^{\circ} \mathrm{C}$.

The oxygen chemisorption in the range of $200-250^{\circ} \mathrm{C}$ is favored when polyethylene is consolidated at high temperature. The weight rise in HTPE is somewhat larger and the peak maximum shifts to a lower temperature compared with the PE specimen. Thus, the HTPE specimen contains a larger number and higher energy surface sites for oxygen chemisorption than PE, which might remind the slightly wider C 1s peak in XPS. The presence of such adsorption sites apparently decreases in the composite material. The GR/HTPE sample shows a progressive weight loss in the range of $100-250^{\circ} \mathrm{C}$, which is not observed in the other three specimens and whose origin is unknown.

The temperature of the great weight loss due to thermal degradation increases in the composite specimens compared to blank PE and HTPE. Therefore, the stability of the polymer matrix increases with the presence of graphene. 


\subsection{Mechanical and morphological properties}

Nano-indentation measurements provided analogous hardness in-depth profiles for all the materials. Figure 7 shows the results for non-irradiated samples and selected materials that underwent significant changes upon $\mathrm{Ar}^{+}$ion sputtering. The profiles present a relatively high starting value that monotonously decreases until reaching a nearly constant level at depths of $1000-1500 \mathrm{~nm}$. The extreme hardening under the initial contact is typical in polymers, and is considered an unreal behaviour associated to the indentation tool size, certain detection errors and pressure effects [35]. Therefore, we will focus on the hardness at $1500 \mathrm{~nm}$, which is already stable and suffers from much less detection errors than the initial reading [36]. The value in the deep indentation region can be considered as a macroscopic hardness indicator.

The $\mathrm{Ar}^{+}$bombardment produces an increase in the standard deviation of the hardness profile, which might indicate an uneven distribution of the sputtering ion flow on the target surface (Figure 7.b). For the non-irradiated samples, the hardness sequence is GR/PE > GR/HTPE > PE, pointing out a positive contribution of graphene, as well as the high temperature conformation of the composite, to matrix hardening, in agreement with a previous work [26]. The most relevant effect of ion sputtering is a hardness increase in all the materials, which reaches up to twice the untreated specimens (Figure 8). In addition, Figure 8 indicates that hardening is not linear with the ion energy, but the effect seems to saturate at intermediate energies in all the materials. The highest hardness value is observed for PE-2000. Less clear is the effect of the accumulative experiment at $5000 \mathrm{eV}$ : the hardness of PE-5000A is quite higher than that of PE-5000 (one step experiment), while it remains nearly unchanged for GR/PE-5000A, and it also increases for GR/HTPE5000.

In order to validate nanoindenter measurements, Vickers hardness was obtained. These results present a lower dispersion than the nanoindenter ones and provide information 
about a large area on the surface. Vickers results, which are shown in Figure 9, confirm the hardness sequence of the nanoindenter for non-irradiated materials, and also reflect the non-linear increase in hardness with the ion energy. Besides, Vickers data point out that the highest increase appears in PE when the ion energy reaches values around $2500 \mathrm{eV}$. Concerning the elastic modulus, nano-indentation provided an in-depth profile (not shown) similar to hardness (Figure 7), in agreement with recent observations on amorphous polymers [37]. The modulus of GR/PE is $10 \%$ higher than that of PE, while the effect of the filler is negligible on the GR/HTPE composite (Figure 10). The influence of $\mathrm{Ar}^{+}$sputtering on the stiffness is noticeable for the three materials, with a maximum increase of around $60 \%$ for PE and $30 \%$ for the GR/HTPE. In spite of the high dispersion in nanoindentation data, the trends point out an increase in the modulus followed by a plateau at voltages above $2000-2500 \mathrm{eV}$.

Our findings also reveal topography changes in all the materials (Figure 11). The behavior upon $\mathrm{Ar}^{+}$sputtering is influenced by the filler. In $\mathrm{PE}$, the $R_{\mathrm{a}}$ value increases from $250 \mathrm{~nm}$ up to approximately $300 \mathrm{~nm}$ for PE-2500. In untreated GR/PE and GR/HTPE composites, the presence of graphene intrinsically provides an increase in $R_{\mathrm{a}}$ values to $500-600 \mathrm{~nm}$. Under $\mathrm{Ar}^{+}$ions of above $2500-3000 \mathrm{eV}, R_{\mathrm{a}}$ values decrease to nearly $300 \mathrm{~nm}$.

\subsection{Electrical properties}

The electrical resistance between two point probes at a distance of $2 \mathrm{~mm}$ is plotted on Figure 12. The blank PE specimen is an insulating material with a surface resistance of approximately $10^{15} \Omega$. A drastic change in conduction properties was measured after ion sputtering with energies higher than $3000 \mathrm{eV}$. The resistance decreases by 5 orders of magnitude, down to approximately $10^{10} \Omega$, after a single step treatment at $5000 \mathrm{eV}$ (PE5000 specimen), and further goes down to nearly $10^{8} \Omega$ after the accumulated treatment (PE5000A specimen). 
The electrical behavior of the GR/PE composite with respect to the $\mathrm{Ar}^{+}$bombardment energy was different from the unfilled PE in three aspects: the change in the surface resistance is more pronounced, with a reduction by 11 orders of magnitude, down to the

level of $10^{4} \Omega$, after sputtering at $5000 \mathrm{eV}$; besides, the transition in the GR/PE composite was sharper than in PE, and appeared at lower values of the acceleration voltage, close to $1700 \mathrm{eV}$.

Finally, the surface resistance of the untreated GR/HTPE composite indicates a loss of the insulating character. The measured resistance was $\sim 10^{4} \Omega$, instead of the $10^{15} \Omega$ of the GR/PE composite, and no changes were observed upon $\mathrm{Ar}^{+}$treatment.

\section{Discussion}

The explanation of the above described mechanical, electrical, chemical and morphological phenomenology should be related to micro/nanoscale effects of positive ions impacting on polymer surfaces at energies up to a few $\mathrm{keV}$. While these effects depend on many parameters, including the polymer composition and structure, and the kind, energy and incidence angle of the ions, the energy transfer from $\mathrm{Ar}^{+}$ions to the polymer typically generates chain scission as a primary relevant effect that evolves to cross-linking, branching or double-bond formation. Besides, the removal of carbon atoms and dehydrogenation at the outermost polymer layer can occur, leading to a graphitized surface $[16,17]$.

In this work, three spectroscopic techniques, namely, XPS, IR and Raman, show the formation of $\mathrm{C}=\mathrm{C}$ double bonds and the graphitization of the polyethylene surface upon $\mathrm{Ar}^{+}$sputtering. A change in the chemical state of the carbon atom, from tetrahedral $\left(\mathrm{sp}^{3}\right)$ to planar $\left(\mathrm{sp}^{2}\right)$ is monitored by XPS. Typically, mechanisms of the transformation involve bond breakage and the formation of radical species that may undergo radical reactions [38]. While the process starts soon after irradiation with very low energy ions, a transition 
occurs at a given energy level around $3000 \mathrm{eV}$. In IR spectra, a decrease in the intensity of methylene peaks and the appearance of the trans-vinylene peak are observed. Both effects can be indirectly associated to cross-linking reactions between polyethylene chains. The surface graphitization leads to an increase in the reactivity towards oxygen and thus to the generation of various types of oxygen chemical groups such as hydroxyl and carbonyl. Besides, signals that might be associated to graphitization are observed in Raman spectra, most specifically a broad band at around the position of the graphite $\mathrm{G}$ band $\left(\sim 1600 \mathrm{~cm}^{-1}\right)$. The XPS analysis on the GNP powder shows the transformation of graphitic carbon $\left(\mathrm{sp}^{2}\right)$ into tetrahedral $\left(\mathrm{sp}^{3}\right)$ by ion sputtering at energies below $2000 \mathrm{eV}$. Indirectly, XPS suggests the generation of defects in the graphene lattice. Similar conclusions can be drawn from Raman spectra on GR/PE and GR/HTPE in the graphene zone. The relative intensity of the $\mathrm{D}$ band increases and the $2 \mathrm{D}$ decreases as a consequence of the number of defects and the distortion of the graphene crystal structure respectively.

The presence of a graphene additive in the polymer matrix changes the response under ion beam irradiation. The effects are detected in two ways: in the intrinsic properties of graphene, and in the interaction between graphene and the polymer matrix. It has to be noted that the effect of $\mathrm{Ar}^{+}$sputtering on polyethylene and graphene are opposite in terms of the carbon atom symmetry. Carbon atoms in polyethylene change from tetrahedral $\mathrm{sp}^{3}$ to planar $\mathrm{sp}^{2}$, while carbon atoms in graphene change from planar graphitic to tetrahedral. Therefore, the effects in a composite material should reflect the combination of both opposite trends. However, in the XPS analysis of GR/PE and GR/HTPE, the contribution of graphene appears more remarkable than expected from its mass ratio (4.6 wt.\%). In fact, the starting $\mathrm{sp}^{2}$ component area for the composites is in the range of 15 to $40 \%$, possibly because of the high aspect ratio of graphene flakes. The final $\mathrm{sp}^{2}$ area in the composites is between 30 and $75 \%$, instead of the $80 \%$ that is reached in ion sputtered PE. In addition, the transition that is clearly observed in pure PE, from 10 to $80 \%$ at $\sim 3000$ 
$\mathrm{eV}$, nearly disappears in GR/PE and GR/HTPE. These observations might be related to the graphene ability of trapping radicals, which ultimately hinders the symmetry change of polyethylene carbon atoms. In the literature, it has been widely described that graphene can easily react with free radicals [39]. The scavenger effect has been also observed when graphene and related materials are subjected to gamma irradiation, either in the presence of other reactive chemical species or acting as a reinforcement in composite materials [4043].

In the present work, it is shown that the thermal degradation temperature in GR/PE and GR/HTPE specimens is substantially higher than PE and HTPE materials. In the literature, this effect has been associated to various causes: an improvement in the thermal conductivity and heat dissipation ability, a decrease in the chain mobility, a hindered release of degradation products, and the graphene ability of trapping free radicals $[38,44]$. In a previous work, we did not measure substantial improvements in the thermal conductivity of poly(ether ether ketone) with the addition of the same type of GNPs, even at loadings up to $10 \mathrm{wt} \%$ [45]. Therefore, we consider that the change in the thermal degradation temperature might be an indirect evidence of the radical scavenging activity of GNPs in the GR/PE and GR/HTPE materials. Further information of radical trapping mechanisms can be deduced from the IR analysis on ion sputtered specimens. Apparently, the relative intensity of oxygen chemical groups at 3420 and $1400-1100 \mathrm{~cm}^{-1}$, as well as the transvinylene peak at $965 \mathrm{~cm}^{-1}$, in the composites is lower than in $\mathrm{Ar}^{+}$sputtered PE. Therefore, some of the reactive species in ion sputtered PE can be neutralized by trapping in graphene, and might evolve to either an internal transformation in the graphene flake or new bonds between graphene and polyethylene chains. While changes in the filler are here detected by Raman spectroscopy, no clear evidence of graphene-polyethylene reactions is registered by spectroscopic methods. 
Another effect of irradiation on polymers, which has been studied in the context of exposure to plasma for lithography and etching applications, is the surface smoothing or roughening as a consequence of competitive mechanisms between vertical motion of the interface and lateral diffusion of chemical species [46, 47]. Specifically, surface roughening in UHMWPE has been observed after a treatment with Ar plasma [48]. It was suggested that the treatment selectively removes the amorphous part of the polymer and uncovers crystalline domains on the surface, thus increasing the roughness [48]. In the present work, a qualitative assessment of surface crystallinity can be performed from IR spectra, since it is known that crystallinity in polyethylene might be associated to the intensity ratio of the methylene bending bands at $1473 / 1463 \mathrm{~cm}^{-1}$ [49]. In fact, a decrease in the intensity ratio is observed by $\mathrm{Ar}^{+}$sputtering on the $\mathrm{PE}$ material, suggesting an increase in surface crystallinity that might be related to roughness. Regarding the effect of crystallinity on the mechanical properties, a positive contribution to the Young's modulus is possible, while the influence on hardness is not expected to be as important as other structural changes, which will be discussed later.

In the present work, the $R_{\mathrm{a}}$ parameter in GR/PE and GR/HTPE composites is higher than that in the PE material. However, ion sputtering causes opposite changes in the neat polymer and the composites, leading to similar $R_{\mathrm{a}}$ values after irradiation at $\sim 2000 \mathrm{eV}$. Apparently, ion sputtering can level the rippled surface of graphene edges in the composites.

From all the micro-structural effects of ion sputtering on polymers, chain cross-linking is likely the most influential one on the surface mechanical properties. The increase in hardness upon $\mathrm{Ar}^{+}$sputtering can be associated to a loss of chain mobility, which hinders the amorphous deformation modes, as it has been reported for gamma and electron beam irradiated UHMWPE [50]. The increase in modulus can be also related to the crosslinking density, which probably produces and increase in stiffness. However, the fact that both 
parameters (hardness and modulus) achieve a saturation value at a given ion acceleration energy (Figures 8-10) is not a common behavior in the literature [46].

$\mathrm{Ar}^{+}$bombardment creates defects in single-layered graphene that induce plastic deformation [51]. Accordingly, Fedorov et al. calculated that Young's modulus should be inversely proportional to the concentration of vacancies [52]. However, an experimental work on a suspended graphene layer under $\mathrm{Ar}^{+}$sputtering at a low energy of $140 \mathrm{eV}$ pointed out that the existence of defects also supresses the flexural modes, resulting in a stiffness maximum with respect to the defect density [13]. Besides, atomistic simulations of graphene under $\mathrm{Ar}^{+}$irradiation with energies ranging from 0.03 to $1000 \mathrm{keV}$ indicated that the highest probability for the generation of single and double vacancies is between 0.1 and $1 \mathrm{keV}$ [5]. In a multi-layered graphene such as GNPs, the irradiation induces vacancies in the inner interlayers [7], with a subsequent cross-linking between layers that attenuates the loss of flake mechanical properties. A similar effect has been reported in carbon nanotubes [51].

As above described, the incorporation of GNPs into polyethylene produced an increase in both the hardness and modulus. However, ion sputtering on GR/PE only generated an increase in hardness, while the modulus did not reveal discernible differences with respect to the non-irradiated material. The mild incidence of ion sputtering on the mechanical properties of the composite seems to be connected to the interaction between graphene and the polymer, rather than to the aforementioned changes in the intrinsic properties of graphene. The GNPs might react with some of the free radicals that are created by chain scission during ion sputtering, causing a reduction in the polymer crosslink density, and consequently smoothing the increase in hardness and practically cancelling the effect on stiffness.

The mechanical behavior of GR/HTPE after argon ion irradiation has to be also discussed in terms of the polymer matrix microstructure. The hot pressing of UHMWPE powders 
results in a granular appearance because of the extremely high viscosity of UHMWPE. Typically, carbon nanoparticles locate at granule frontiers, but do not form a random distribution in the matrix [53]. The use of increasingly high temperatures for UHMWPE consolidation was introduced by Fu et al. with the idea of improving toughness by means of an increase in plasticity [54]. Microstructurally, the effect would be obtained by the diffusion of polymeric chains through the granule edges. An increase in polyethylene plasticity might cause a decrease in hardness. However, in the present work, the increase in the consolidation temperature does not produce substantial changes in the surface hardness under ion beam sputtering. Only a recovery of the modulus after ion beam treatments up to $3000 \mathrm{eV}$ might be deduced from our measurements on GR/HTPE (Figure $10)$.

Concerning the electrical behavior, the most relevant result is the transition that is observed in PE and GR/PE specimens. In PE, the substantial decrease in the resistance at high $\mathrm{Ar}^{+}$acceleration voltages reminds previous literature data on other systems such as polypropylene under a low-pressure plasma of noble gas ions [20]. In that work, the plasma induced changes in the surface that caused a 6-8 orders of magnitude drop in the resistance. The dose parameter resulted to be more important than the applied radiofrequency potential, which ranged from 0 to $190 \mathrm{~V}$. In our work, the reduction in the resistance was about 5 orders of magnitude after a single step process at $5000 \mathrm{eV}$, and 7 orders of magnitude in the accumulated experiment. Since the accumulated process means a higher flow of incident ions, our results also point out an influence of the ion dose on conductivity, apart from the ion acceleration potential.

Changes in the conductance of polymer surfaces seem to be typically related to the graphitization that takes place by ion bombardment at given energy and dose parameters. In our case, the strong increase in $\mathrm{sp}^{2}$ carbon, which is observed by XPS at similar ion energies (Figure 2) to the transition in resistance (Figure 12), the rise in the trans-vinylene 
band $\left(965 \mathrm{~cm}^{-1}\right)$ in the IR analysis, and the appearance of the $\mathrm{C}=\mathrm{C}$ band $\left(1600 \mathrm{~cm}^{-1}\right)$ in Raman spectra seem to be relevant causes behind the increase in conductance. The IR detection of hydroxyl $\left(3420 \mathrm{~cm}^{-1}\right)$, carbonyl $\left(1713 \mathrm{~cm}^{-1}\right)$ and alcohol/phenol $\left(1300 \mathrm{~cm}^{-1}\right)$ groups might be also related to the change in the electrical properties.

Usually, conductance modifications in polymers are interpreted in terms of the percolation theory and hopping processes. This interpretation leads to the typical expression: $\sigma \sim(\Phi$ $\left.\Phi_{c}\right)^{\mathrm{t}}$, where $\sigma$ is the conduction property, t is a critical index and $\Phi_{c}$ is a percolation critical parameter. Depending on the considered phenomenon, the $\Phi$ parameter stands for the concentration of conductive fillers in an insulating polymer [55] or the flow of incident ions in polymers under plasma or ion bombardment [20]. In our case, we have not succeeded in obtaining a $\Phi_{c}$ parameter, which would have been associated to $E_{\mathrm{Ar}}$, because of the small number of experimental data above the conductivity transition.

The GR/PE composite shows an insulating behavior with resistance values around $10^{15} \Omega$, indicating that the GNP filler concentration of $4.6 \mathrm{wt} \%$ is below the percolation threshold [26]. Besides, the $\mathrm{Ar}^{+}$treatment produces changes in the GR/PE microstructure that increase the conductivity by $10-12$ orders of magnitude at ion sputtering energies around $1700 \mathrm{eV}$. The surface resistance drops to $10^{4} \Omega$ and approaches the limit of $10^{2} \Omega$ that is measured on the surface of a pure GNP pellet. The resistance variation reminds other polymer composites with carbon fillers at concentrations above the percolation $[55,56]$. Therefore, the formation of an electrical network in the GR/PE composite is easier than in the unfilled PE. In GR/PE, the relatively small change in $\mathrm{sp}^{2}$ carbon (Figure 2c), transvinylene groups and $\mathrm{C}=\mathrm{C}$ bonds, which are observed by XPS, IR and Raman spectra respectively, seem to be enough to obtain a complete network in the presence of conductive GNP particles. Also, the fact that the transition to the low resistance is so fast might be related to a GNP concentration approaching the percolation concentration. 
Finally, the GR/HTPE composite shows an electric behavior notably different from PE and GR/PE. The untreated GR/HTPE composite already has a low value of resistance. The change in the consolidation temperature from $175^{\circ} \mathrm{C}$ to $240^{\circ} \mathrm{C}$ converts the composite from an insulating material with $10^{15} \Omega$ into a conductive material with $10^{4} \Omega$. While the influence of the manufacturing process on the percolation concentration has been observed in the literature [57], the conductance change with the consolidation temperature, drastic in the present work, has not been reported so far. It is known that the increase in the consolidation temperature of UHMWPE to $280-320{ }^{\circ} \mathrm{C}$ creates certain microstructural changes that have an influence on mechanical properties, in particular on plasticity and impact toughness [54]. However, changes in polyethylene grain boundaries, which arise from an increase in the self-diffusion of molecular chains, do not apparently increase the conductivity of the unfilled HTPE, which remains identical to PE at the level of $10^{15} \Omega$. Therefore, the abrupt change in conductivity would be again associated to the proximity of the GNP concentration to the critical percolation, at which the material is very sensitive to the consolidation temperature. Although the involved mechanism is difficult to elucidate, our experimental data shows related phenomena by XPS spectra and thermal analysis. The XPS C 1s band in the untreated GR/HTPE is substantially different from GR/PE (Figure 1). The graphene $\mathrm{sp}^{2}$ contribution in GR/PE is relatively small and clearly separated from the tetrahedral $\mathrm{sp}^{3}$ component. However, the $\mathrm{sp}^{2}$ contribution in the untreated GR/HTPE reaches $>30 \%$ (Figure 2), and the $\mathrm{sp}^{2}$ and $\mathrm{sp}^{3}$ contributions are quite near from each other in terms of BEs. Regarding the thermal behavior (insight in Figure 6), the GR/HTPE sample begins to loss its weight at around $80{ }^{\circ} \mathrm{C}$, while the other materials maintain their weight until the beginning of the small but noticeable gain at $225^{\circ} \mathrm{C}$, in agreement with previous works [34]. A change in the interaction between graphene and polyethylene must occur, via functionalization of the matrix, which introduces changes in the thermal behavior and besides allows the activation of the conductivity network. To deepen in the 
particular mechanism is out of the scope of this work, but should be considered in further investigations. On the other hand, the GR/HTPE conductivity is not altered by sputtering in the studied range of energies and ion flows. Basically, the electrical network has been already established in the untreated sample and no improvement is expected in spite of the possible changes due to ion bombardment.

\section{Conclusions}

Ion beam sputtering between 500 and $5000 \mathrm{eV}$ was performed on the surface of graphene/polyethylene composites. These treatments induce noticeable structural, morphological and mechanical changes.

Structural changes in blank PE are evidenced by shifts in the XPS C 1s peak to the position of $\sim 284.5 \mathrm{eV}$ and the shape profile changes after $\mathrm{Ar}^{+}$irradiation. A relevant transformation occurs in a narrow range of $\mathrm{Ar}^{+}$energies around $3000 \mathrm{eV}$, which is related to the conversion of tetrahedral $\mathrm{sp}^{3}$ into planar $\mathrm{sp}^{2}$ carbon. Concurrently, new transvinylene groups are detected by IR spectroscopy, and a broad band at $\sim 1600 \mathrm{~cm}^{-1}$, which might be associated to $\mathrm{C}=\mathrm{C}$ bonds, appears in Raman spectra. Also, oxygen groups such as carbonyl, carboxyl and alcohol/phenol are detected on sputtered samples after the exposure to air. The presence of graphene in the polymer matrix hinders the transformation of $\mathrm{sp}^{3}$ to $\mathrm{sp}^{2}$ carbon in the polyethylene surface. This effect might be related to the radical trapping ability of graphene, which is evidenced by changes in the thermo-oxidative behavior in thermogravimetric experiments.

$\mathrm{The}^{+}{ }^{+}$irradiation on graphene powders produces a loss of the $\mathrm{sp}^{2}$ character, because of the formation of defective $\mathrm{sp}^{3}$ centers in the flakes. This fact is reflected in Raman spectra by an increase in the $\mathrm{I}_{\mathrm{D}} / \mathrm{I}_{\mathrm{G}}$ ratio, and a decrease in the $\mathrm{I}_{2 \mathrm{D}} / \mathrm{I}_{\mathrm{G}}$ ratio.

Mechanical properties of the surface are also modified upon irradiation with $\mathrm{Ar}^{+}$. Vickers hardness, nanoindentation hardness and nanoindentation modulus of the composites 
increase by $30-100 \%$ with respect to the untreated samples, for PE and the composites as well; however, the effect saturates at around $2000 \mathrm{eV}$ of incident energy in all the cases. Regarding the influence of $\mathrm{Ar}^{+}$energy on the surface roughness, an opposite behavior is observed on the raw PE and the composites: the average roughness increases in PE while it decreases in both GR/PE and GR/HTPE.

More relevant changes occur in the electrical conductivity. The insulator character of the pure PE surface, which shows a high electrical resistance $\left(10^{15} \Omega\right)$, decreases by 5 orders of magnitude to $10^{10} \Omega$ for sputtering treatments with energies higher than $4000 \mathrm{eV}$. However, the electrical conductance of graphene/polyethylene composites depends on the consolidation temperature: the surface of the GR/PE composite shows an abrupt transition from insulating $\left(10^{15} \Omega\right)$ to conducting $\left(10^{4} \Omega\right)$ at $\mathrm{Ar}^{+}$sputtering energies in the range of 1750-3000 eV, while the conductance of the GR/HTPE material is directly limited by the

filler at the level of $10^{4} \Omega$, and does not substantially change upon ion beam sputtering up to $5000 \mathrm{eV}$.

\section{ACKNOWLEDGEMENTS}

Special thanks are directed to the Analysis Service of Instituto de Carboquimica ICBCSIC, in particular to Mr. I. Fernández, Ms. D. Domingo and Ms. A.I. Díaz. This work has been funded by the Spanish Ministry of Science and the European Regional Development Fund (ENE 2016-79282-C5-1-R), and the Government of Aragon together with the European Social Fund (DGA ESF T48-17R and T03-17R). 
Table 1. Specimen labels indicating conditions of the consolidation process and the argon ion treatment: $T_{\mathrm{c}}=$ consolidation temperature; $E_{\mathrm{Ar}}=$ energy of the $\mathrm{Ar}^{+}$ion beam. Polyethylene (PE) always means UHMWPE, and GR stands for the GNP material in the composites.

\begin{tabular}{llll}
\hline Specimen label & $\left.\boldsymbol{T}_{\mathbf{c}}{ }^{\circ} \mathbf{C}\right]$ & Ar $^{+}$mode & $\boldsymbol{E}_{\mathrm{Ar}}[\mathbf{e V}]^{\mathrm{a}}$ \\
\hline GNP- $E_{\mathrm{Ar}} \mathrm{A}$ & Powder & Accumulated & $500+1000+1500+2000+2500+3000+4000+5000$ \\
PE & 175 & Untreated & - \\
PE- $E_{\mathrm{Ar}}$ & 175 & One step & $500,1000,2000,2500,3000,4000,5000$ \\
PE- $E_{\mathrm{Ar}} \mathrm{A}$ & 175 & Accumulated & $1750+1750+2000+2500+3000+4000+5000$ \\
HTPE & 240 & Untreated & - \\
GR/PE & 175 & Untreated & - \\
GR/PE- $E_{\mathrm{Ar}}$ & 175 & One step & $1500,1750,2000,2500,4000,5000$ \\
GR/PE- $E_{\mathrm{Ar}} \mathrm{A}$ & 175 & Accumulated & $3500+3500+4000+5000+5000$ \\
GR/HTPE & 240 & Untreated & - \\
GR/HTPE- $E_{\mathrm{Ar}}$ & 240 & One step & $1500,2000,2500,3500,4000,5000$ \\
GR/HTPE- $E_{\mathrm{Ar}} \mathrm{A}$ & 240 & Accumulated & $500+1000+1500+2000+2500+3500+4000+5000$ \\
\hline${ }^{\mathrm{a}} \mathrm{Steps}$ of $300 \mathrm{~s}$ & & & \\
\hline
\end{tabular}




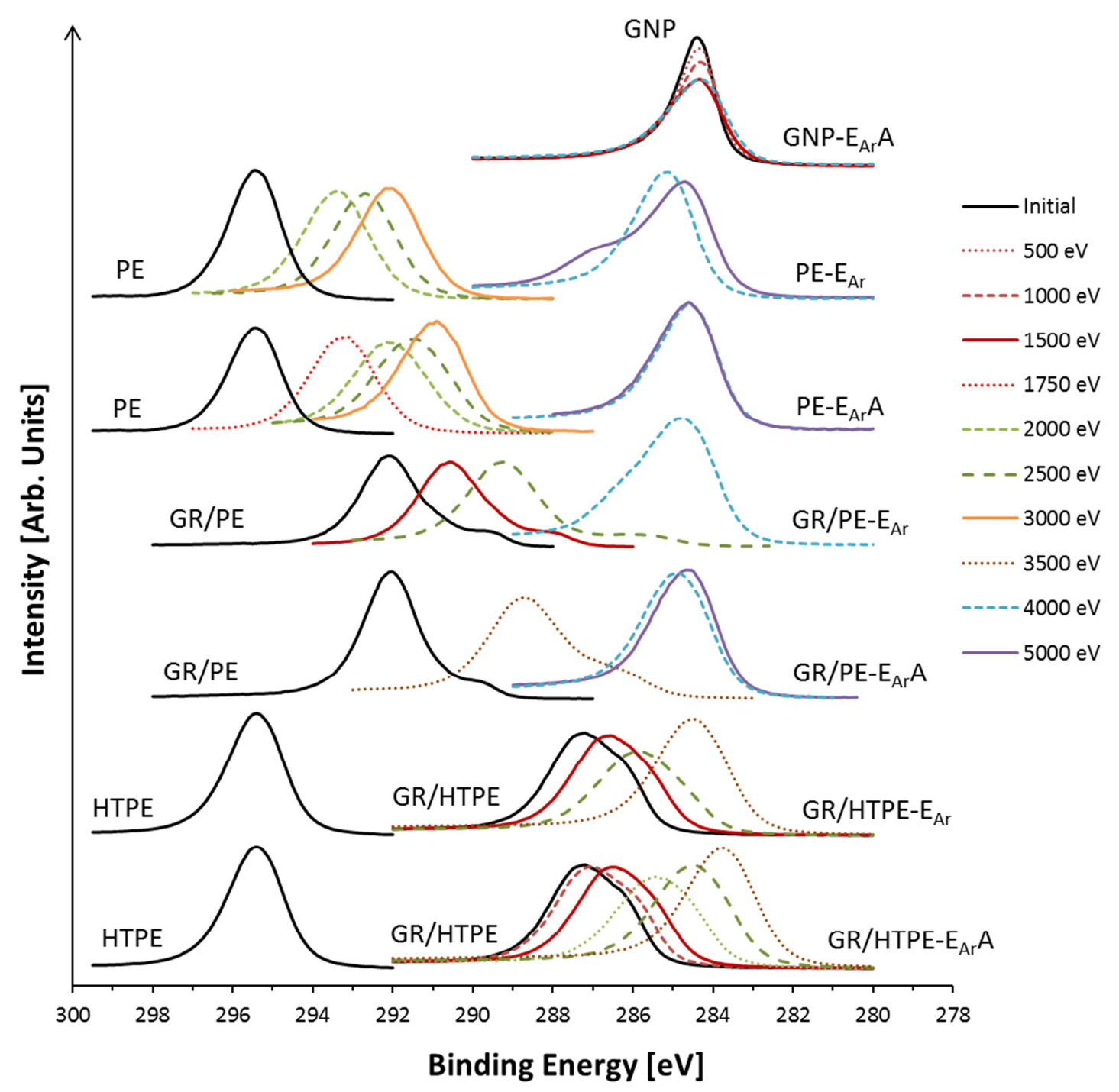

FIGURE 1. High resolution C 1s XPS spectrum of the GNP powder, blank PE, GR/PE and GR/HTPE composites, and evolution with the Ar ion gun treatment at various energies in both one step and accumulated modes. 

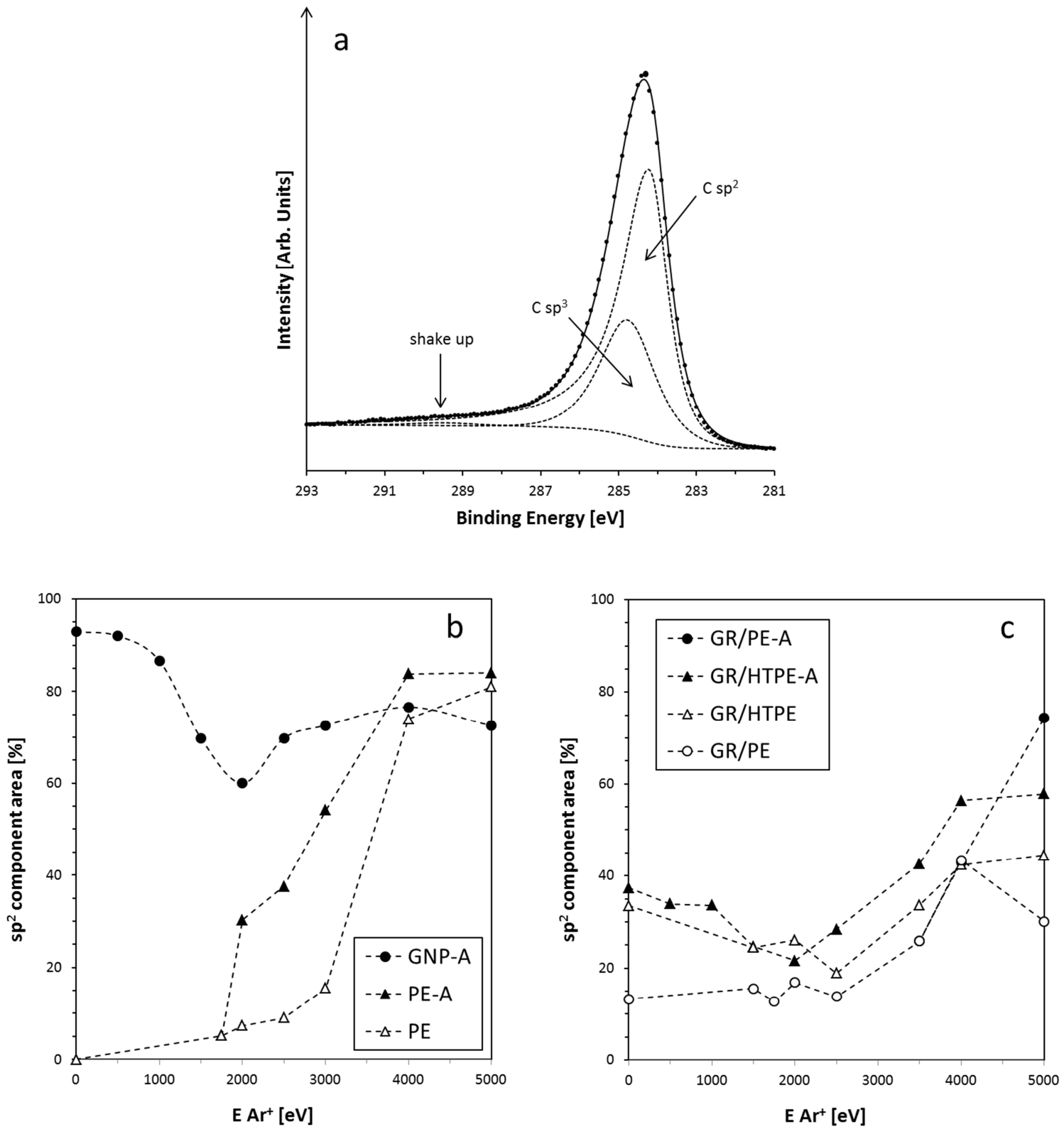

FIGURE 2. XPS analysis of GNP powders, PE, GR/PE and GR/HTPE composites upon treatment with the $\mathrm{Ar}^{+}$gun: a) an example of deconvolution of the high resolution $\mathrm{C} 1 \mathrm{~s}$ spectrum for GNP-1500A; and b, c) areal percentages of the $\mathrm{sp}^{2} \mathrm{C}$ component. 

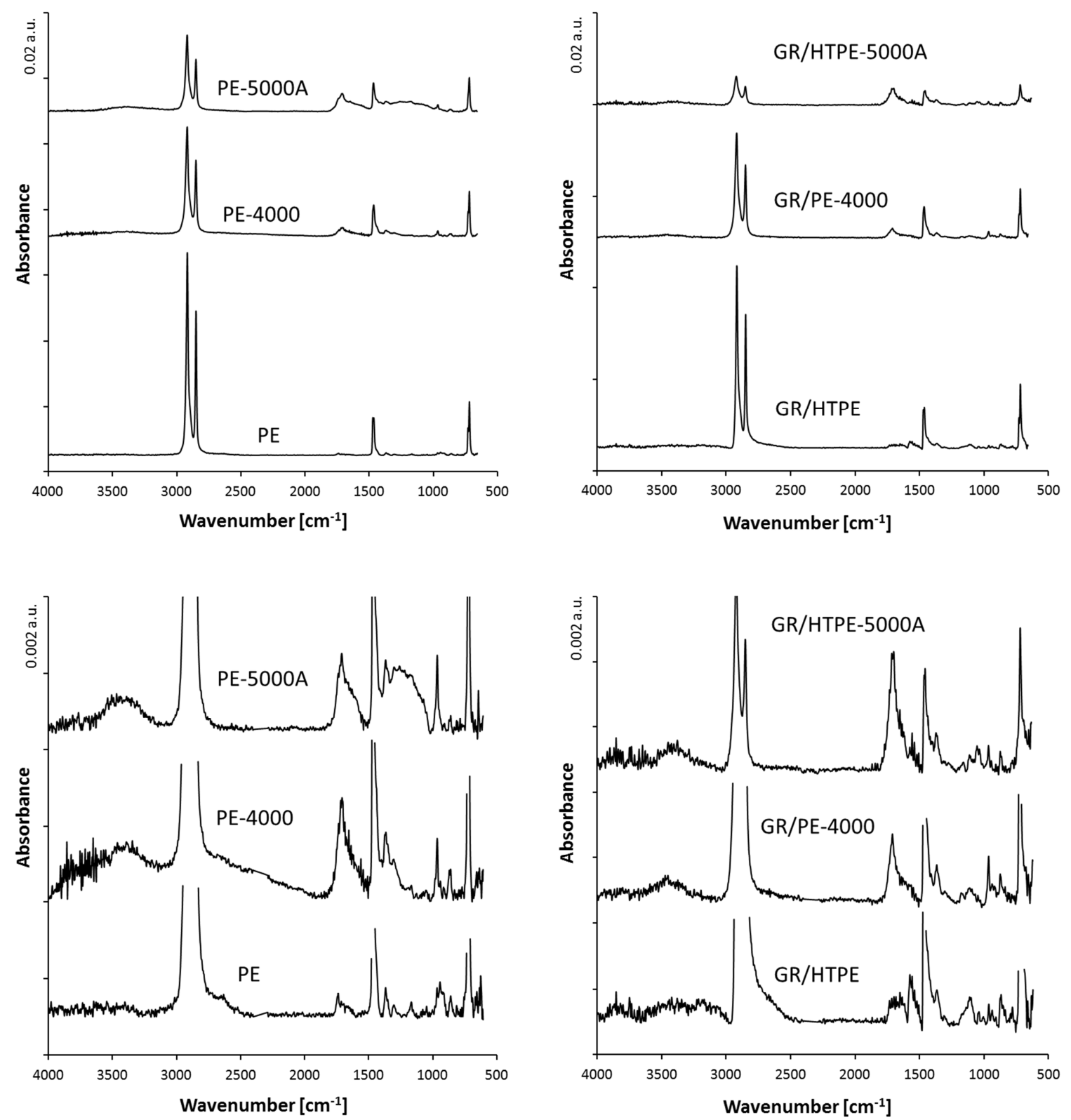

FIGURE 3. Representative IR spectra showing the effect of the $\mathrm{Ar}^{+}$gun: examples of PE (left), and GR/PE or GR/HTPE composites (right). Top graphs include the complete spectra while bottom graphs enlarge the low absorbance region. Specimen names follow criteria of Table 1. On the Y-axis, a.u. stands for absorbance units. 


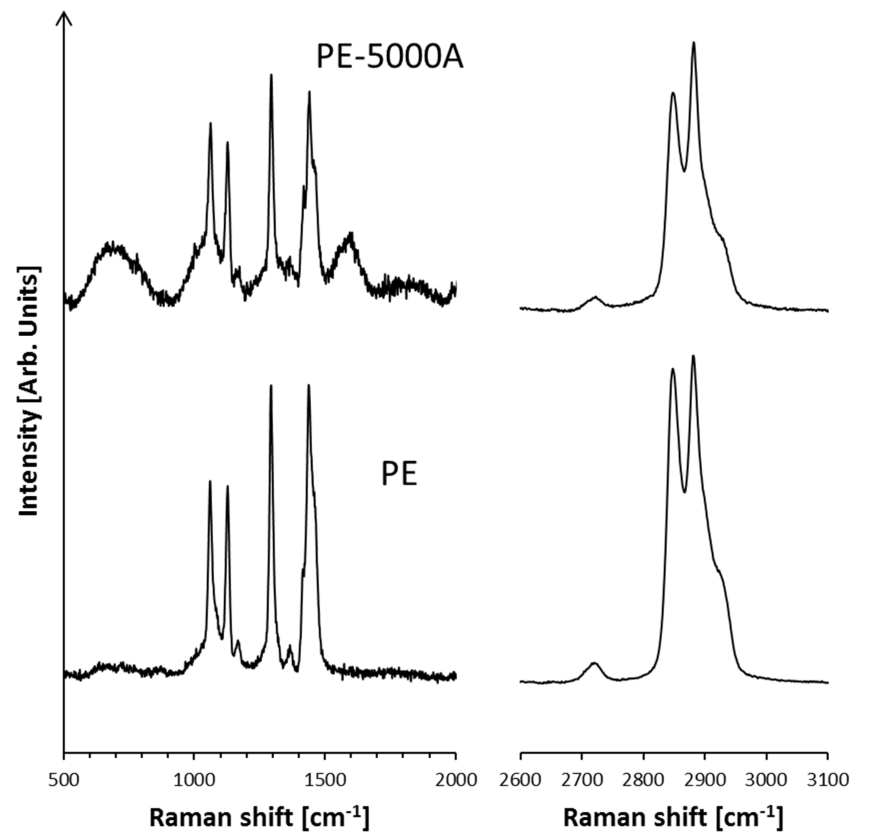

FIGURE 4. Raman spectra of PE (down) and PE treated with the $\mathrm{Ar}^{+}$ion beam (top). 


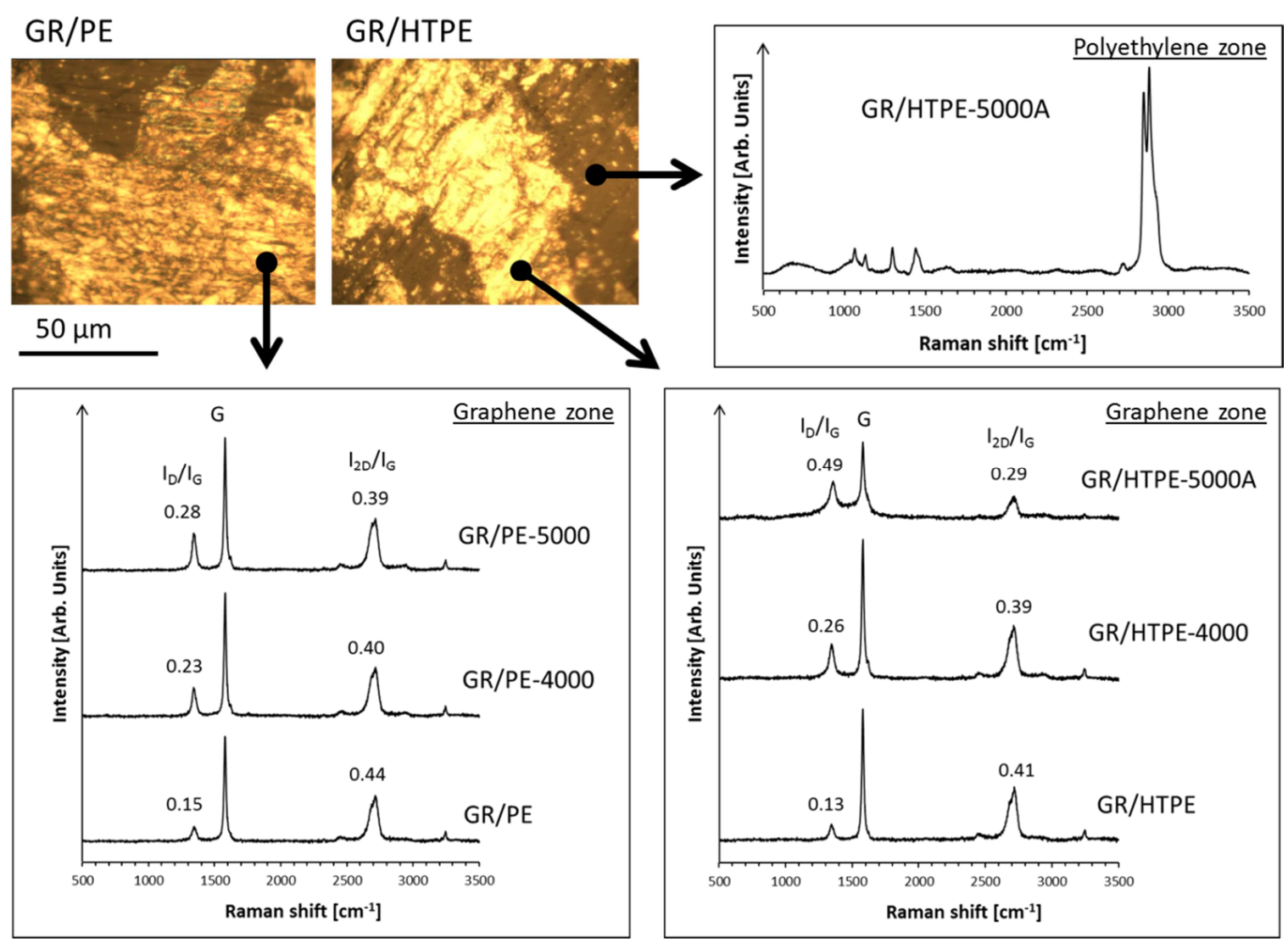

FIGURE 5. Raman analysis of GR/PE and GR/HTPE composites upon treatment with the $\mathrm{Ar}^{+}$ion beam: representative optical images (top left) point the typical areas where the Raman characteristics of polyethylene (top right) and graphene (bottom) are followed respectively. 


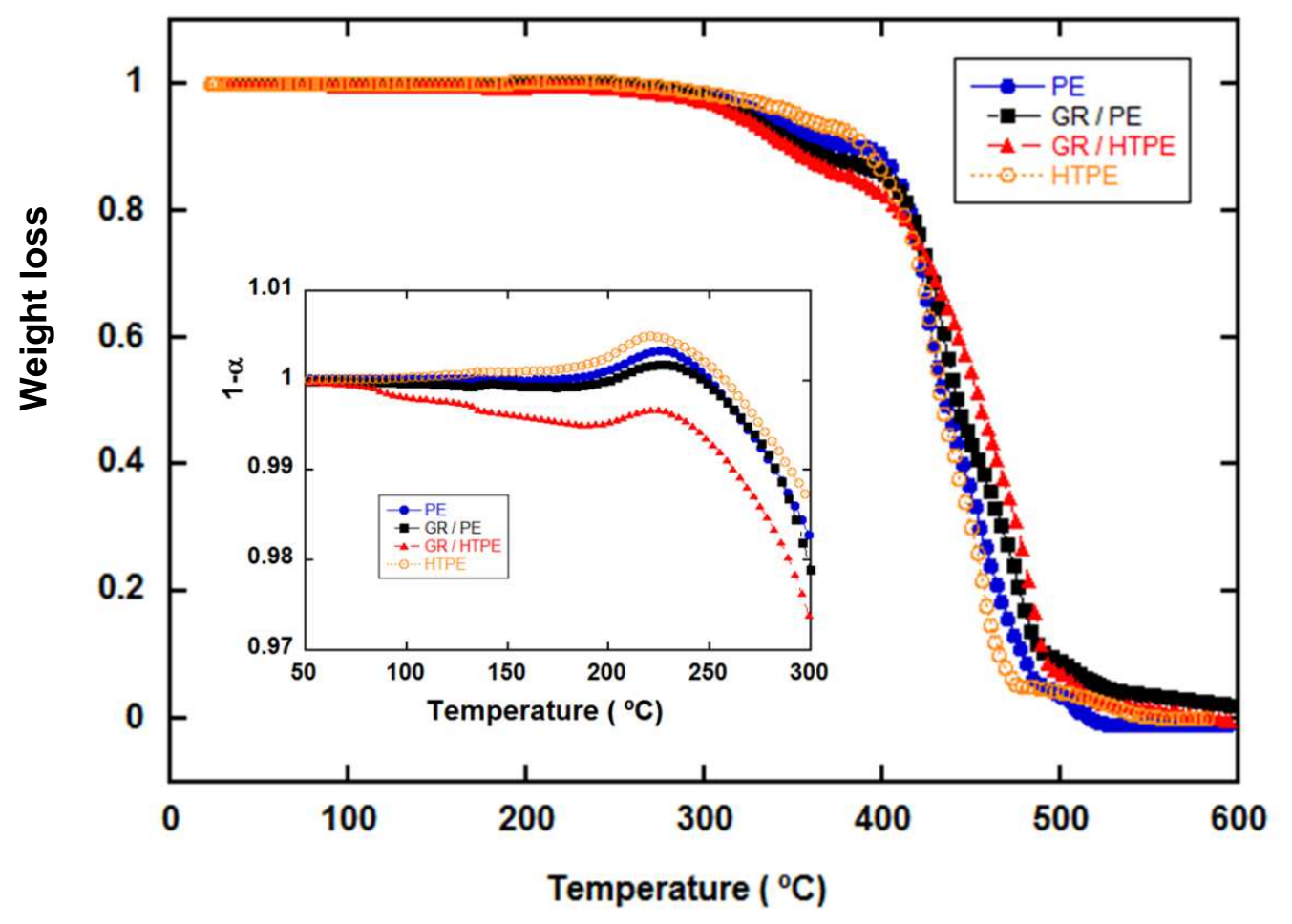

FIGURE 6. Thermogravimetric curves for non-irradiated control samples: (•) PE, (匹) GR/PE, $(\Delta)$ GR/HTPE, and ( $($ ) HT/PE. A close-up view (insight) revealed small but noticeable weight gains at around $225^{\circ} \mathrm{C}$. 

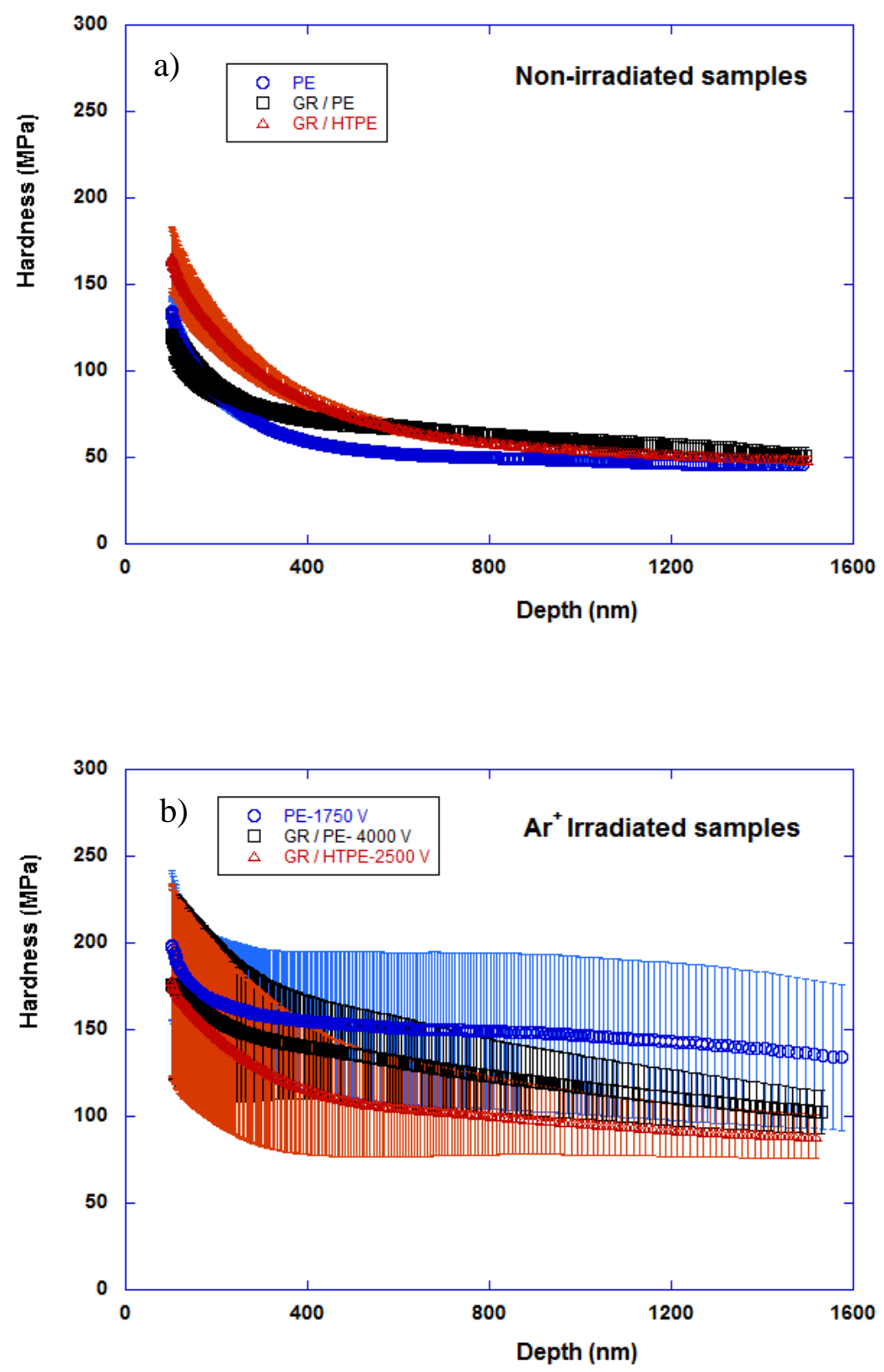

FIGURE 7. In-depth hardness profiles for: a) the starting PE resin and graphene-based composites; b) the argon-sputtered samples resulting in the maximum values of hardness. 


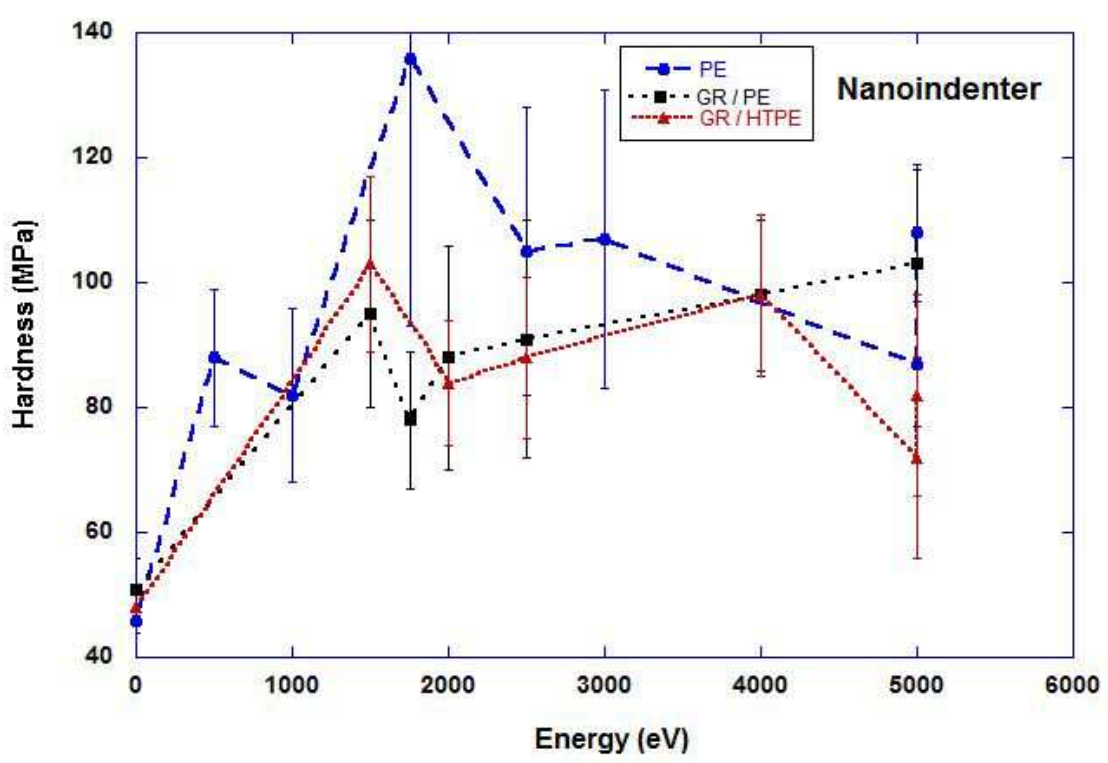

FIGURE 8. Average hardness at $1500 \mathrm{~nm}$ in depth obtained by a nanoindenter vs the acceleration energy of $\mathrm{Ar}^{+}$ions. 


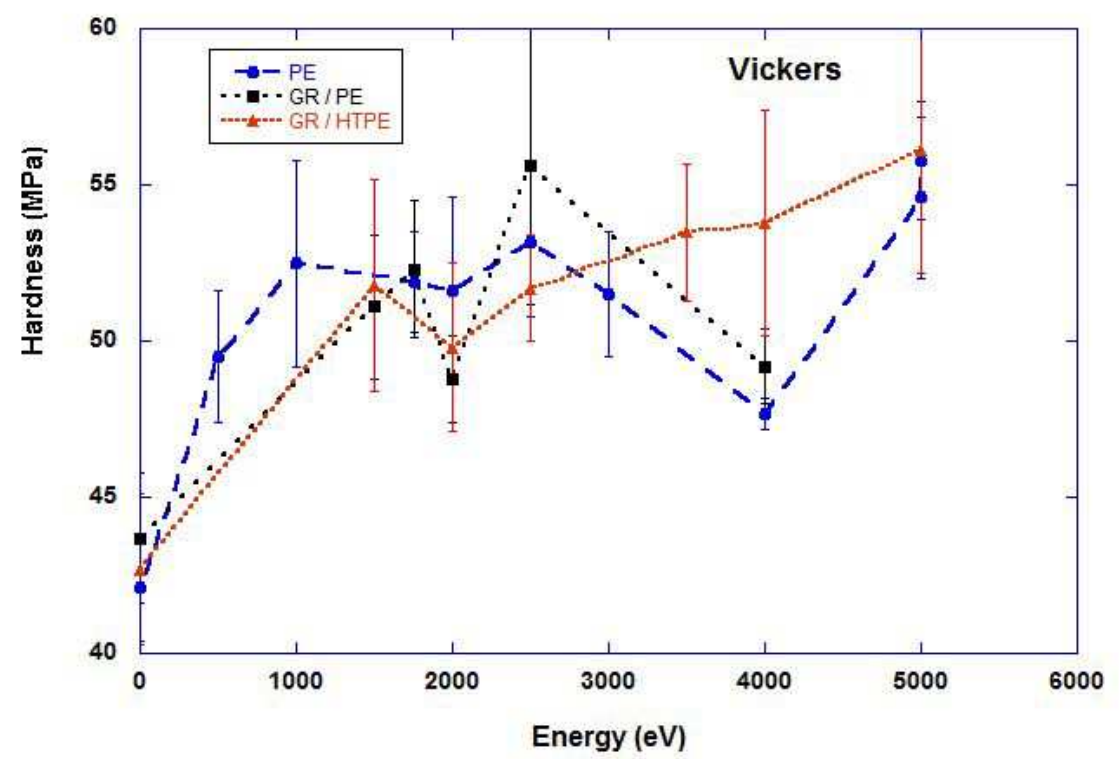

FIGURE 9. Vickers hardness of the raw matrix and the composities vs the acceleration energy of $\mathrm{Ar}^{+}$ions. 


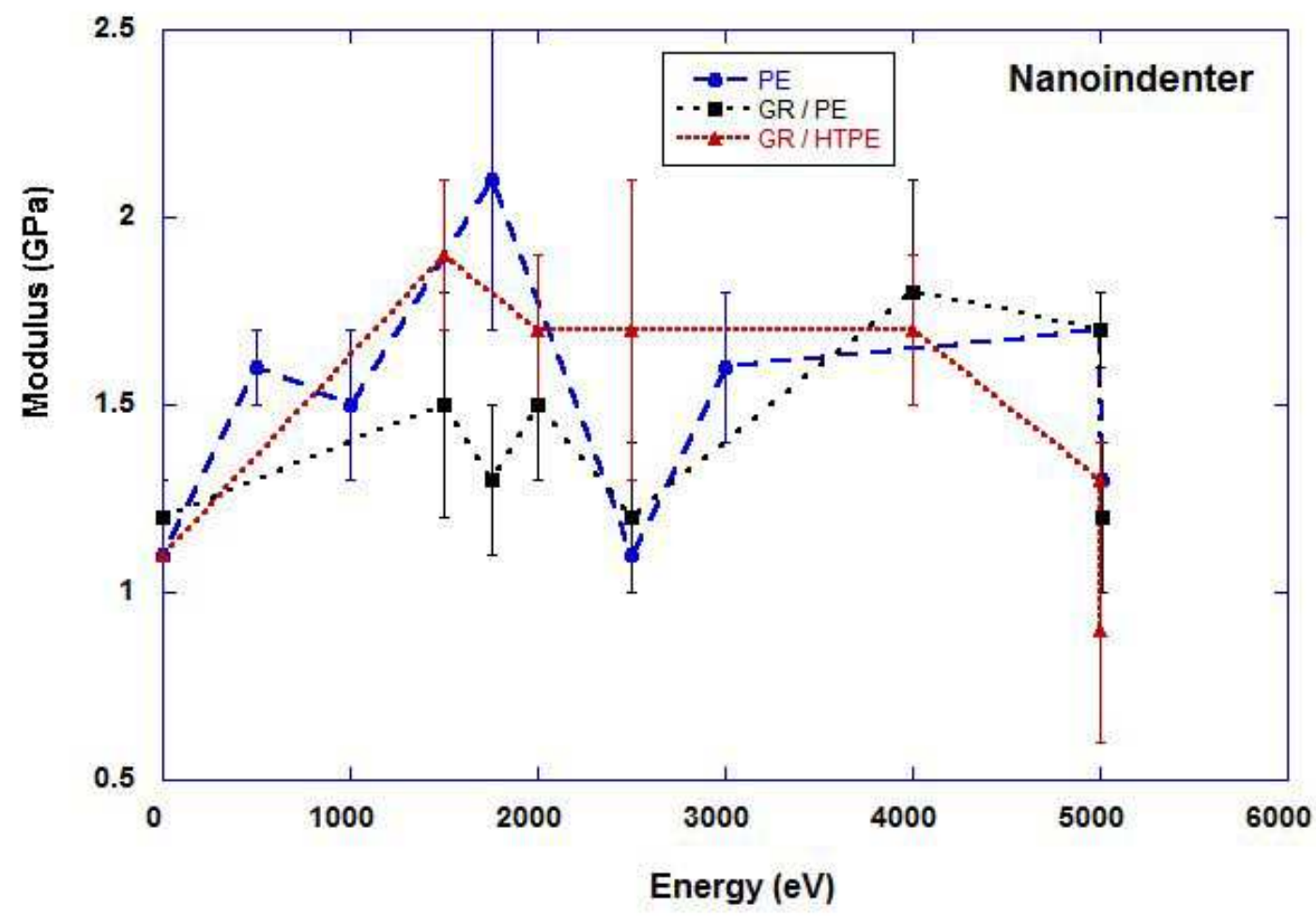

FIGURE 10. Average elastic modulus at $1500 \mathrm{~nm}$ in-depth obtained by nanoindenter vs the acceleration energy of $\mathrm{Ar}^{+}$ions. 


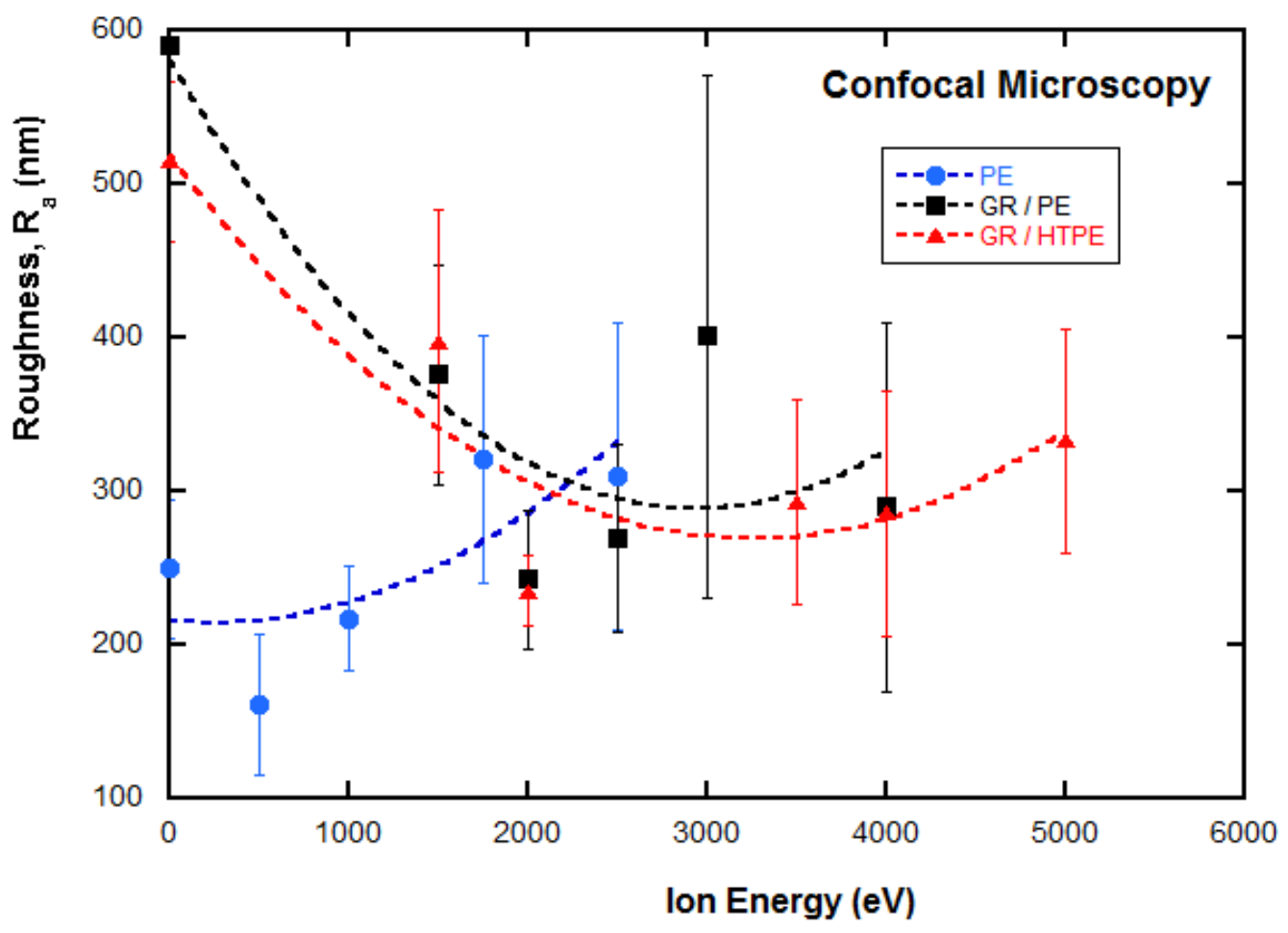

FIGURE 11. Influence of the ion energy on the average roughness, $R_{a}$, in PE and in the composites reinforced with graphene GR/PE and GR/HTPE. Dashed lines are eye-guides. 


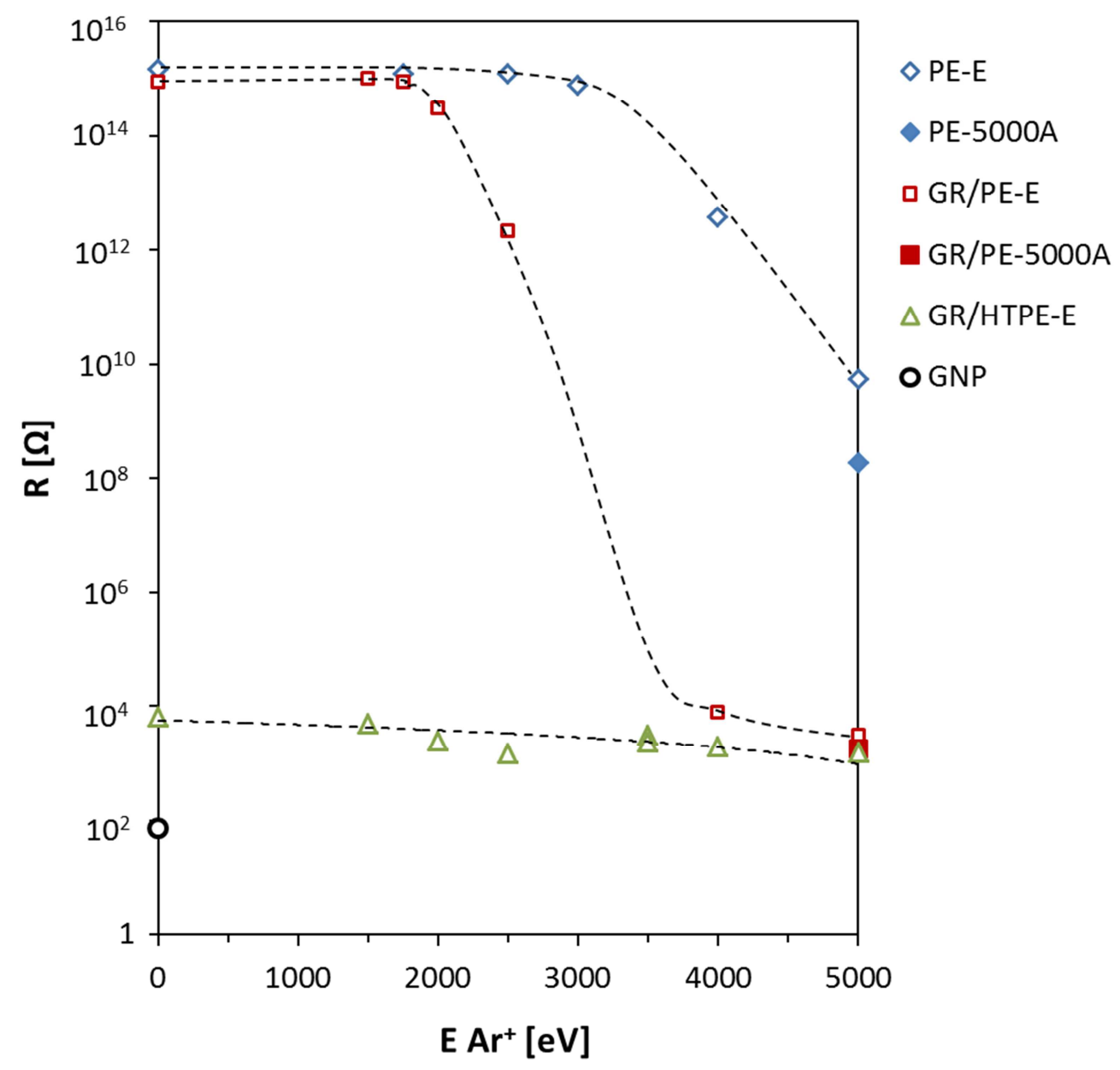

FIGURE 12. Surface electrical resistance between two point probes at a distance of $2 \mathrm{~mm}$ for PE, GR/PE and GR/HTPE upon treatment with the $\mathrm{Ar}^{+}$gun. Dashed lines are eyeguides. 


\section{REFERENCES}

[1] L. Vicarelli, S.J. Heerema, C. Dekker, H.W. Zandbergen, Controlling defects in graphene for optimizing the electrical properties of graphene nanodevices, ACS Nano, 9 (2015) 3428-3435.

[2] L.L. Liu, M.Q. Qing, Y.B. Wang, S.M. Chen, Defects in graphene: generation, healing, and their effects on the properties of graphene: a review, J Mater Sci Technol, 31 (2015) 599-606.

[3] M.A. Bissett, S. Konabe, S. Okada, M. Tsuji, H. Ago, Enhanced chemical reactivity of graphene induced by mechanical strain, ACS Nano, 7 (2013) 10335-10343.

[4] J.C. Meyer, A. Chuvilin, U. Kaiser, Electron microscopic studies with graphene, microsc microanal, 15 (2009) 126-127.

[5] O. Lehtinen, J. Kotakoski, A.V. Krasheninnikov, A. Tolvanen, K. Nordlund, J.

Keinonen, Effects of ion bombardment on a two-dimensional target: Atomistic simulations of graphene irradiation, Phys Rev B, 81 (2010) 153401.

[6] A. Jorio, M.M. Lucchese, F. Stavale, E.H.M. Ferreira, M.V.O. Moutinho, R.B. Capaz, C.A. Achete, Raman study of ion-induced defects in N-layer graphene, J Phys-Condens Mat, 22 (2010) 334204.

[7] M. Kalbac, O. Lehtinen, A.V. Krasheninnikov, J. Keinonen, Ion-irradiation-induced defects in isotopically-labeled two layered graphene: enhanced in-situ annealing of the damage, Adv Mater, 25 (2013) 1004-1009.

[8] J.R. Xiao, J. Staniszewski, J.W. Gillespie, Fracture and progressive failure of defective graphene sheets and carbon nanotubes, Compos Struct, 88 (2009) 602-609.

[9] L.Q. Xu, N. Wei, Y.P. Zheng, Mechanical properties of highly defective graphene: from brittle rupture to ductile fracture, Nanotechnology, 24 (2013) 505703.

[10] C. Daniels, A. Horning, A. Phillips, D.V.P. Massote, L.B. Liang, Z. Bullard, B.G.

Sumpter, V. Meunier, Elastic, plastic, and fracture mechanisms in graphene materials, J Phys-Condens Mat, 27 (2015) 373002.

[11] G. Lopez-Polin, J. Gomez-Herrero, C. Gomez-Navarro, Confining crack propagation in defective graphene, Nano Lett, 15 (2015) 2050-2054.

[12] A.V. Krasheninnikov, F. Banhart, Engineering of nanostructured carbon materials with electron or ion beams, Nat Mater, 6 (2007) 723-733.

[13] G. Lopez-Polin, C. Gomez-Navarro, V. Parente, F. Guinea, M.I. Katsnelson, F. Perez-Murano, J. Gomez-Herrero, Increasing the elastic modulus of graphene by controlled defect creation, Nat Phys, 11 (2015) 26-31.

[14] H.W. Chen, M.M. Wu, C. Li, Structural integrity versus lateral size: Enhancing graphene-based film materials by reducing planar defects rather than flake boundary, Carbon, 139 (2018) 216-225.

[15] G.V. Bianco, A. Sacchetti, C. Ingrosso, M.M. Giangregorio, M. Losurdo, P.

Capezzuto, G. Bruno, Engineering graphene properties by modulated plasma treatments, Carbon, 129 (2018) 869-877.

[16] A. Delcorte, Modeling keV particle interactions with molecular and polymeric samples, Nucl Instrum Meth B, 236 (2005) 1-10.

[17] J.J. Vegh, D.B. Graves, Molecular dynamics simulations of $\mathrm{Ar}^{+}$-organic polymer interactions, Plasma Process Polym, 6 (2009) 320-334.

[18] P. Bodo, J.E. Sundgren, Adhesion of evaporated titanium films to ion-bombarded polyethylene, J Appl Phys, 60 (1986) 1161-1168.

[19] A. Hollander, M. Haupt, C. Oehr, On depth profiling of polymers by argon ion sputtering, Plasma Process Polym, 4 (2007) 773-776. 
[20] M.C. Coen, P. Groening, G. Dietler, L. Schlapbach, Creation of a conductive surfacelayer on polypropylene samples by low-pressure plasma treatments, J Appl Phys, 77 (1995) 5695-5701.

[21] J. Puertolas, S. Kurtz, Evaluation of carbon nanotubes and graphene as reinforcements for UHMWPE-based composites in arthroplastic applications: A review, Journal of the Mechanical Behavior of Biomedical Materials, 39 (2014) 129-145. [22] A. Chaichi, A. Prasad, L. Parambil, S. Shaik, A. Ettefagh, V. Dasa, S. Guo, M. Osborn, R. Devireddy, M. Khonsari, M. Gartia, Improvement of tribological and biocompatibility properties of orthopedic materials using piezoelectric direct discharge plasma surface modification, ACS Biomaterials Science \& Engineering, 5 (2019) 21472159.

[23] F. Bretagnol, H. Rauscher, M. Hasiwa, O. Kylian, G. Ceccone, L. Hazell, A. Paul, O. Lefranc, F. Rossi, The effect of sterilization processes on the bioadhesive properties and surface chemistry of a plasma-polymerized polyethylene glycol film: XPS characterization and L929 cell proliferation tests, Acta Biomaterialia, 4 (2008) 1745-1751.

[24] F. Leipold, N. Schultz-Jensen, Y. Kusano, H. Bindslev, T. Jacobsen,

Decontamination of objects in a sealed container by means of atmospheric pressure plasmas, Food Control, 22 (2011) 1296-1301.

[25] S. Tripathi, G. Rao, A. Mathur, R. Jasra, Polyolefin/graphene nanocomposites: a review, Rsc Advances, 7 (2017) 23615-23632.

[26] A. Chih, A. Anson-Casaos, J.A. Puertolas, Frictional and mechanical behaviour of graphene/UHMWPE composite coatings, Tribol Int, 116 (2017) 295-302.

[27] J.L. Figueiredo, M.F.R. Pereira, The role of surface chemistry in catalysis with carbons, Catal Today, 150 (2010) 2-7.

[28] F. Sette, G.K. Wertheim, Y. Ma, G. Meigs, S. Modesti, C.T. Chen, Lifetime and screening of the C1s photoemission in graphite, Phys Rev B, 41 (1990) 9766-9770. [29] D. Pantea, H. Darmstadt, S. Kaliaguine, L. Summchen, C. Roy, Electrical conductivity of thermal carbon blacks - Influence of surface chemistry, Carbon, 39 (2001) 1147-1158.

[30] D.Q. Yang, E. Sacher, Carbon 1s X-ray photoemission line shape analysis of highly oriented pyrolytic graphite: The influence of structural damage on peak asymmetry, Langmuir, 22 (2006) 860-862.

[31] J.A. Leiro, M.H. Heinonen, T. Laiho, I.G. Batirev, Core-level XPS spectra of fullerene, highly oriented pyrolitic graphite, and glassy carbon, J Electron Spectrosc, 128 (2003) 205-213.

[32] N.N. Kumar, S.L. Yap, F.N.D.B. Samsudin, M.Z. Khan, R.S.P. Srinivasa, Effect of argon plasma treatment on tribological properties of UHMWPE/MWCNT nanocomposites, Polymers-Basel, 8 (2016) 295.

[33] J.B. Wu, M.L. Lin, X. Cong, H.N. Liu, P.H. Tan, Raman spectroscopy of graphenebased materials and its applications in related devices, Chem Soc Rev, 47 (2018) 18221873.

[34] M.J. Martinez-Morlanes, F.J. Medel, M.D. Mariscal, J.A. Puertolas, On the assessment of oxidative stability of post-irradiation stabilized highly crosslinked UHMWPEs by thermogravimetry, Polym Test, 29 (2010) 425-432.

[35] A.M. Diez-Pascual, M.A. Gomez-Fatou, F. Ania, A. Flores, Nanoindentation in polymer nanocomposites, Prog Mater Sci, 67 (2015) 1-94.

[36] Z.Y. Qian, J. Risan, B. Stadnick, G.B. McKenna, Apparent depth-dependent modulus and hardness of polymers by nanoindentation: Investigation of surface detection error and pressure effects, J Polym Sci Pol Phys, 56 (2018) 414-428. 
[37] G.Z. Voyiadjis, L. Malekmotiei, A. Samadi-Dooki, Indentation size effect in amorphous polymers based on shear transformation mediated plasticity, Polymer, 137 (2018) 72-81.

[38] E. Tarani, Z. Terzopoulou, D.N. Bikiaris, T. Kyratsi, K. Chrissafis, G. Vourlias, Thermal conductivity and degradation behavior of HDPE/graphene nanocomposites, $\mathrm{J}$ Therm Anal Calorim, 129 (2017) 1715-1726.

[39] P.A. Denis, Density functional investigation of thioepoxidated and thiolated graphene, Journal of Physical Chemistry C, 113 (2009) 5612-5619.

[40] A. Anson-Casaos, J.A. Puertolas, F.J. Pascual, J. Hernández-ferrer, P. Castell, A.M. benito, W.K. Kaser, M.T. Martínez, The effect of gamma irradiaition on few-layered graphene materials, Applied Surface Science, 301 (2014) 264-272.

[41] W. Xia, H.R. Xue, J.W. Wang, T. Wang, L. Song, H. Guo, X.L. Fan, H. Gong, J.P. $\mathrm{He}$, Functionlized graphene serving as free radical scavenger and corrosion protection in gamma-irradiated epoxy composites, Carbon, 101 (2016) 315-323.

[42] Y. Lin, Y.H. Liu, D.G. Zhang, G.Z. Wu, Radiation resistance of polypropylene composites by incorporating reduced graphene oxide and antioxidant: comparison study, Composites Science and Technology, 146 (2017) 83-90.

[43] Y. Qiu, Z.Y. Wang, A.C.E. Owens, I. Kulaots, Y.T. Chen, A.B. Kane, R.H. Hurt, Antioxidant chemistry of graphene-based materials and its role in oxidation protection technology, Nanoscale, 6 (2014) 11744-11755.

[44] L. Melk, N. Emami, Mechanical and thermal performances of UHMWPE blended vitamin E reinforced carbon nanoparticle composites, Compos Part B-Eng, 146 (2018) 2027.

[45] J.A. Puertolas, M. Castro, J.A. Morris, R. Rios, A. Anson-Casaos, Tribological and mechanical properties of graphene nanoplatelet/PEEK composites, Carbon, 141 (2019) 107-122.

[46] R.L. Bruce, F. Weilnboeck, T. Lin, R.J. Phaneuf, G.S. Oehrlein, B.K. Long, C.G. Willson, J.J. Vegh, D. Nest, D.B. Graves, Relationship between nanoscale roughness and ion-damaged layer in argon plasma exposed polystyrene films, J Appl Phys, 107 (2010) 084310 .

[47] G.S. Oehrlein, R.J. Phaneuf, D.B. Graves, Plasma-polymer interactions: A review of progress in understanding polymer resist mask durability during plasma etching for nanoscale fabrication, J Vac Sci Technol B, 29 (2011) 010801.

[48] Z. Novotna, S. Rimpelova, P. Jurik, M. Vesely, Z. Kolska, T. Hubacek, T. Ruml, V. Svorcik, The interplay of plasma treatment and gold coating and ultra-high molecular weight polyethylene: On the cytocompatibility, Mat Sci Eng C-Mater, 71 (2017) 125-131. [49] G. Zerbi, G. Gallino, N. Delfanti, L. Baini, Structural depth profiling in polyethylene films by multiple internal-reflection infrared-spectroscopy, Polymer, 30 (1989) 23242327.

[50] L.A. Pruitt, Deformation, yielding, fracture and fatigue behavior of conventional and highly cross-linked ultra high molecular weight polyethylene, Biomaterials, 26 (2005) 905-915.

[51] A.V. Krasheninnikov, K. Nordlund, Ion and electron irradiation-induced effects in nanostructured materials, J Appl Phys, 107 (2010) 071301.

[52] A.S. Fedorov, Z.I. Popov, D.A. Fedorov, N.S. Eliseeva, M.V. Serjantova, A.A.

Kuzubov, DFT investigation of the influence of ordered vacancies on elastic and magnetic properties of graphene and graphene-like SiC and BN structures, Physica Status Solidi BBasic Solid State Physics, 249 (2012) 2549-2552.

[53] P.G. Ren, Y.Y. Di, Q. Zhang, L. Li, H. Pang, Z.M. Li, Composites of ultrahighmolecular-weight polyethylene with graphene sheets and/or MWCNTs with segregated 
network structure: preparation and properties, Macromolecular Materials and Engineering, 297 (2012) 437-443.

[54] J. Fu, B.W. Ghali, A.J. Lozynsky, E. Oral, O.K. Muratoglu, Ultra high molecular weight polyethylene with improved plasticity and toughness by high temperature melting, Polymer, 51 (2010) 2721-2731.

[55] J.A. Puertolas, J.F. Garcia-Garcia, F.J. Pascual, J.M. Gonzalez-Dominguez, M.T.

Martinez, A. Anson-Casaos, Dielectric behavior and electrical conductivity of PVDF filled with functionalized single-walled carbon nanotubes, Compos Sci Technol, 152 (2017) 263-274.

[56] A. Anson-Casaos, F.J. Pascual, C. Ruano, N. Fernandez-Huerta, I. Fernandez-Pato, J.C. Otero, J.A. Puertolas, M.T. Martinez, Electrical Conductivity and Tensile Properties of Block-Copolymer-Wrapped Single-Walled Carbon Nanotube/Poly(methyl methacrylate) Composites, J Appl Polym Sci, 132 (2015) 41547.

[57] Z. Spitalsky, D. Tasis, K. Papagelis, C. Galiotis, Carbon nanotube-polymer composites: Chemistry, processing, mechanical and electrical properties, Prog Polym Sci, 35 (2010) 357-401. 